\title{
The antimicrobial activity of nanoparticles: present situation and prospects for the future
}

\author{
This article was published in the following Dove Press journal: \\ International Journal of Nanomedicine \\ 14 February 2017 \\ Number of times this article has been viewed
}

\section{Linlin Wang ${ }^{1, *}$ \\ Chen $\mathrm{Hu}^{2}$,* \\ Longquan Shao ${ }^{2}$}

'Department of Stomatology, Hainan General Hospital, Haikou, Hainan, 2Department of Stomatology, Nanfang Hospital, Southern Medical University, Guangzhou, People's Republic of China

*These authors contributed equally to this work
Correspondence: Longquan Shao Department of Stomatology, Nanfang Hospital, Southern Medical University, Guangzhou 5I05I5, People's Republic of China

Tel +86206278 7l53

Email shaolongquan@smu.edu.cn

\begin{abstract}
Nanoparticles (NPs) are increasingly used to target bacteria as an alternative to antibiotics. Nanotechnology may be particularly advantageous in treating bacterial infections. Examples include the utilization of NPs in antibacterial coatings for implantable devices and medicinal materials to prevent infection and promote wound healing, in antibiotic delivery systems to treat disease, in bacterial detection systems to generate microbial diagnostics, and in antibacterial vaccines to control bacterial infections. The antibacterial mechanisms of NPs are poorly understood, but the currently accepted mechanisms include oxidative stress induction, metal ion release, and non-oxidative mechanisms. The multiple simultaneous mechanisms of action against microbes would require multiple simultaneous gene mutations in the same bacterial cell for antibacterial resistance to develop; therefore, it is difficult for bacterial cells to become resistant to NPs. In this review, we discuss the antibacterial mechanisms of NPs against bacteria and the factors that are involved. The limitations of current research are also discussed.
\end{abstract}

Keywords: antimicrobial activity, nanoparticles, oxidative stress, antimicrobial resistance

\section{Introduction}

Bacterial infections are a major cause of chronic infections and mortality. Antibiotics have been the preferred treatment method for bacterial infections because of their cost-effectiveness and powerful outcomes. However, several studies have provided direct evidence that the widespread use of antibiotics has led to the emergence of multidrug-resistant bacterial strains. In fact, super-bacteria, which are resistant to nearly all antibiotics, have recently developed due to abuse of antibiotics. Studies have shown that these bacteria carry a super-resistance gene called NDM-1. ${ }^{1}$ The major groups of antibiotics that are currently in use have three bacterial targets: the cell wall synthesis, translational machinery, and DNA replication machinery. Unfortunately, bacterial resistance can develop against each of these modes of action. The mechanisms of resistance include expression of enzymes that modify or degrade antibiotics, such as $\beta$-lactamases and aminoglycosides, ${ }^{2}$ modification of cell components, such as the cell wall in vancomycin resistance and ribosomes in tetracycline resistance, ${ }^{3}$ and expression of efflux pumps, which provide simultaneous resistance against numerous antibiotics. ${ }^{4}$ Most of the antibiotic resistance mechanisms are irrelevant for nanoparticles (NPs) because the mode of action of NPs is direct contact with the bacterial cell wall, without the need to penetrate the cell; this raises the hope that NPs would be less prone to promoting resistance in bacteria than antibiotics. Therefore, attention has been focused on new and exciting NP-based materials with antibacterial activity. 
Most bacteria exist in the form of a biofilm, which often contains diverse species that interact with each other and their environment. Biofilms are specifically microbial aggregates that rely on a solid surface and extracellular products, such as extracellular polymeric substances (EPSs). ${ }^{5}$ Bacteria move reversibly onto the surface, but the expression of EPSs renders the attachment irreversible. Once the bacteria are settled, synthesis of the bacterial flagellum is inhibited, and the bacteria multiply rapidly, resulting in the development of a mature biofilm. At this stage, the bacteria are stuck together, forming a barrier that can resist antibiotics and provide a source of systemic chronic infections. Thus, biofilms are a serious health threat. ${ }^{6,7}$ Moreover, the bacteria within biofilms can produce superantigens to evade the immune system. Therefore, despite the abundance of antimicrobial drugs and other modern antibacterial agents, bacterial infections remain a major issue. The chronic infections related to planktonic bacteria and biofilms are always difficult to cure because of their inherent resistance to both antimicrobial agents and host defenses. In particular, biofilms are less restrained by antibacterial agents than the respective planktonic bacteria are. ${ }^{8}$

Nanomaterials are materials that have at least one dimension $(1-100 \mathrm{~nm})$ in the nanometer scale range or whose basic unit in the three-dimensional space is in this range. ${ }^{9}$ NPs in particular have demonstrated broad-spectrum antibacterial properties against both Gram-positive and Gram-negative bacteria. For example, ZnO NPs were found to inhibit Staphylococcus aureus, and Ag NPs exhibit concentrationdependent antimicrobial activity against Escherichia coli and Pseudomonas aeruginosa. ${ }^{10}$ However, the detailed antibacterial mechanisms of NPs have not been thoroughly explained, and the same types of NPs often present contrasting effects. The antimicrobial mechanism of action of NPs is generally described as adhering to one of three models: oxidative stress induction, ${ }^{11}$ metal ion release, ${ }^{12}$ or non-oxidative mechanisms. ${ }^{13}$ These three types of mechanisms can occur simultaneously. Certain studies have proposed that Ag NPs prompt neutralization of the surface electric charge of the bacterial membrane and change its penetrability, ultimately leading to bacterial death. ${ }^{14}$ Moreover, the generation of reactive oxygen species (ROS) inhibits the antioxidant defense system and causes mechanical damage to the cell membrane. According to existing research, the major processes underlying the antibacterial effects of NPs are as follows: 1) disruption of the bacterial cell membrane; 2) generation of ROS; 3) penetration of the bacterial cell membrane; and 4) induction of intracellular antibacterial effects, including interactions with DNA and proteins.
This review focuses on the mechanisms of bacterial resistance and the antibacterial activity of NPs. Investigation of the antibacterial mechanisms of NPs is very important for the development of more effective antimicrobial materials.

\section{Bacterial resistance to NPs}

The primary reason why NPs are being considered as an alternative to antibiotics is that NPs can effectively prevent microbial drug resistance in certain cases. The rampant use of antibiotics has led to the emergence of numerous hazards to public health, such as superbugs that do not respond to any existing drug and epidemics against which medicine has no defense. ${ }^{15}$ The search for new, effective bactericidal materials is significant for combatting drug resistance, and NPs have been established as a promising approach to solve this problem. ${ }^{16-18}$ However, NPs can also promote the emergence of bacterial resistance in certain cases. ${ }^{19}$ In this section, we present the positive and negative aspects of the interactions between NPs and drug-resistant bacteria.

\section{Mechanisms of antimicrobial resistance}

Bacterial resistance has become a serious problem due to the massive application of antibiotics, which are used prophylactically or remedially without proper medical indications; the inappropriate selection of alternate antimicrobials; and the frequent switching between antimicrobial treatments. Drug-fast and multidrug-resistant bacteria have multiple causes that can all be summarized as an interaction of intrinsic and extrinsic factors. The latter factors mainly include the sustained "selection pressure" of antibiotics and ecological changes in the human microenvironment.

In the following sections, we describe the mechanisms of the intrinsic factors from two different angles.

\section{From the angle of genetics at the DNA level}

We first analyze the internal causes at the gene level. Resistance can be divided into intrinsic resistance and acquired resistance according to the source of the resistance genes. Intrinsic resistance can be caused by spontaneous mutation of existing or exogenous genes, whereas acquired resistance is caused by acquisition of resistance genes from another organism. The emergence of multidrug resistance (MDR) in particular is a result of the acquisition of different types of drug resistance genes by the same bacterial cell. ${ }^{20}$ In general, intrinsic resistance is subordinate and less important. There are three ways by which resistance can be transferred and spread between bacteria: plasmids, ${ }^{21,22}$ transposons, ${ }^{23}$ and integrons. ${ }^{24}$ 
From the angle of biochemistry at the protein level Certain resistance mechanisms are a result of changes in proteins, including specific types of enzymes and major targets on the surface of cells. The main mechanisms with respect to biochemistry are 1) the alteration of targets; 2) the generation of inactivated enzymes or passivated enzymes; 3) the use of active efflux pump systems; ${ }^{25,26} 4$ ) the presentation of obstacles to antibiotic permeation; 5) the formation of biofilms; ${ }^{27}$ and 6) the emergence and elimination of a specific protein, such as $\mathrm{BamA}^{28}$ or $\mathrm{KatG},{ }^{29}$ which can affect infection through unknown mechanisms. Certain bacteria show antimicrobial resistance through only one of the mechanisms listed earlier, but two or more mechanisms can also be combined in one type of bacterium, including 7) induction of an antagonist through metabolic pathways or 8 ) increased production of a competitive inhibitor counteracting the antibiotic. ${ }^{15}$

Therefore, in the pre-NP era, three methods used to overcome antibiotic resistance were the development of new drugs, high-dose administration of an antibiotic, ${ }^{6}$ and the combination of multiple antibiotics. ${ }^{30,31}$ However, the production of novel antibiotics could not keep up with the mutation of bacteria, and intolerable toxicity always accompanied high-dose treatment. These treatment strategies also led to antibiotic misuse and the emergence of multidrugresistant strains.

\section{The effects of NPs on microbial resistance}

\section{Positive side: as an effective therapeutic method to} combat microbial resistance and multidrug-resistant mutants

Increasing numbers of NP variants and NP-based materials have been used as a new line of defense against microbial resistance and MDR. ${ }^{32,33}$ Different types of NPs have different mechanisms for combating microbial resistance. Various antibacterial mechanisms of NPs according to the metabolic process involved are presented in the "Antibacterial mechanisms of NPs" section.

One of the accepted relationships between nanomaterials and antibacterial activity is as follows: "Nanomaterials as antibacterial complements to antibiotics are highly promising and are gaining large interest as they might fill the gaps where antibiotics frequently fail." 16 In addition, nanomaterials can complement and support traditional antibiotics "as a good carrier." ${ }^{34}$ This section focuses on the distinct features and complementary advantages of using NPs/nanotechnologies as antibacterial agents compared with traditional antibiotics, which can be summarized as follows: 1) overcoming the existing antibiotic resistance mechanisms that are listed in the "Antibacterial activity of NPs" section including the disruption of bacterial membranes and the hindrance of biofilm formation, ${ }^{17} 2$ ) combatting microbes using multiple mechanisms simultaneously, ${ }^{17}$ and 3) acting as good carriers of antibiotics.

\section{Overcoming the existing antibiotic resistance mechanisms}

Most types of NPs can overcome at least one of the common resistance mechanisms mentioned in the "Antibacterial activity of NPs" section (including the disruption of bacterial membranes and the hindrance of biofilm formation). ${ }^{17}$ These effects are a result of the bactericidal mode of NPs, which is based on their specific physicochemical properties. ${ }^{35}$ In contrast to traditional antibiotics, NPs have characteristic dimensions $<100 \mathrm{~nm}$. Their uniquely small size results in novel properties, such as greater interaction with cells due to a larger surface area-to-mass ratio and versatile and controllable application. ${ }^{6}$

The mechanisms by which NPs disrupt bacterial membranes are described in detail in the "Antibacterial process of NPs" section; rather, the interaction of NPs with cell barriers (including cell walls and membranes) and the synthesis of bacterial proteins are considered in this section. The bacterial cell membrane is difficult to change through only a few genetic mutations because of its highly conserved nature, which further reduces the probability of bacterial drug resistance.

In addition to the disruption of bacterial membranes, hindrance of biofilm formation is an important mechanism, as biofilms play an important part in the development of bacterial resistance. ${ }^{36}$ The unique composition and structure of bacterial biofilms provide shelter or protection to the embedded microorganisms, helping them to escape from most antibiotics. In addition, bacterial biofilms are "a breeding ground" for frequent resistance mutations and the exchange and alteration of these mutations among different bacterial cells. ${ }^{15}$

Studies have shown that many NPs can prevent or overcome biofilm formation, including Au-based NPs, ${ }^{37} \mathrm{Ag}$-based $\mathrm{NPs},{ }^{38} \mathrm{Mg}$-based NPs $,{ }^{39} \mathrm{NO} \mathrm{NPs},{ }^{40,41} \mathrm{ZnO} \mathrm{NPs},{ }^{7} \mathrm{CuO}$ NPs,${ }^{42}$ $\mathrm{Fe}_{3} \mathrm{O}_{4} \mathrm{NPs}{ }^{43}$ and YF NPs. ${ }^{44}$ Greater prevention of biofilms is achieved by a smaller size and higher surface area-to-mass ratio, and the particle shape of NPs also has a remarkable effect on biofilm destruction (eg, NPs with a rod like shape are more effective than NPs with a spherical shape). ${ }^{41}$ 


\section{Combatting microbes using multiple mechanisms simultaneously}

The antimicrobial mechanism of traditional antibiotics is usually relatively simple, which is partly why bacterial resistance has emerged. In contrast to traditional antibiotics, NPs combat microbes via multiple mechanisms that are simultaneously active. The advantage of these simultaneous mechanisms is obvious: a microbe is unlikely to have multiple mutated genes, so it is much more difficult to develop resistance to NPs.

\section{Acting as good carriers of antibiotics}

NPs not only can combat bacterial and microbial resistance themselves, as mentioned earlier, but also can act as a "medium and carrier" of antibiotics. However, the mechanisms of NP-based drug delivery are different from those presented earlier.

Several types of NPs are currently used for drug delivery: liposomal NPs, ${ }^{45}$ solid lipid (SL) NPs ${ }^{46,47}$ polymer-based NPs, polymer micelles, inorganic nanodrug carriers (including magnetic NPs, mesoporous silica NPs, carbon nanomaterials, and quantum dots), terpenoid-based NPs ${ }^{48}$ and dendrimer NPs. ${ }^{49}$

As a carrier for the delivery of antibiotics, the main advantages of NPs compared with conventional delivery systems are as follows:

Size: The ultra-small and controllable size of NPs is suitable for conducting antimicrobial operations and combating intracellular bacteria. ${ }^{50}$

The treatment of infections caused by intracellular pathogens and strains with drug resistance is more complex using antibiotics ${ }^{51}$ because of antibiotics' poor membrane transport. Drugs of average size thus have little effect on intracellular microbes. A modified treatment method using drug-loaded NPs as intermediaries has been proposed to overcome this limitation. The size of most types of NPs is so small that they are easily phagocytosed by host phagocytes. Moreover, the structures of many types of NPs are suitable for carrying drugs (such as liposomal NPs, whose walls are composed of one or more lipid bilayers surrounding sphereshaped NPs), ${ }^{52}$ and the flexibility of NPs to enter host cells via endocytosis makes it possible for most of the drug to be released intracellularly.

Protection: NP carriers can help to increase the serum levels of antibiotics and protect the drugs from resistance by target bacteria.

Within NP carriers, drugs are protected from detrimental chemical reactions; thus, the potency of the drugs can be maintained. In addition, protection from the resistance mechanisms of the target bacteria is an important mechanism. ${ }^{6}$

Increased efflux and decreased uptake of antibiotics in bacterial cells (such as in P. aeruginosa and E. coli) are two common and important reasons for resistance to traditional antibiotics. However, researchers have shown that many NPs can overcome these mechanisms, ${ }^{18}$ inhibiting drug resistance. For example, in the gastrointestinal tract, dendrimers can inhibit P-glycoprotein-mediated efflux. ${ }^{49}$

Precision and security: NP carriers can help to target antibiotics to an infection site and thereby minimize systemic side effects.

It is difficult to encourage high-dose drug absorption at the desired site while preventing side effects (including drug toxicity) when using conventional antibiotics without a carrier. NP-based antibacterial drug delivery systems deliver the drug to the site of action and therefore reduce the side effects. The undesired adverse effects of antibiotics on the body are specifically weakened because of the higher dose delivered to the site of infection.

Targeted NP-based drug delivery consists of passive targeting or active targeting. Passive targeting is achieved through enhanced permeation and retention at the infection site, and active targeting is achieved though surface modification of NPs, allowing the NP-based drug delivery system to selectively recognize specific ligands on the cells at the infection site. Active targeting includes receptor targeting, magnetic targeting, and temperature targeting.

Vancomycin strongly inhibits Gram-positive bacteria. However, vancomycin has strong ear and kidney toxicity. One way to improve treatment would be to increase drug delivery to the desired location, thus limiting the amount of drug reaching organs where it is unnecessary. With the help of NP carriers, vancomycin-modified mesoporous silica NPs (MSNs is a subset of Van) were designed, which made it possible to detect and kill pathogenic Gram-positive bacteria selectively over macrophage-like cells. ${ }^{52}$

An effective and crucial strategy frequently employed to achieve "target therapy" is to first target macrophages with NPs because most active bacteria at infection sites can be targeted and swallowed by macrophages. The drugs in the NPs are then released in the macrophages in which bacteria are present. ${ }^{53}$

Controllability: Sustained and controllable release of antibiotics can be achieved flexibly.

With a conventional delivery method, the blood drug level is maintained for a short time in a relatively large range that can exceed the maximal tolerated dose or fail to 
reach the lowest effective dose. As a result, repeated dosing is indispensable, with associated side effects. With the appropriate NP carrier or method of drug release, the blood concentration of the medicine at the infection site can be sustained at the required effective level for a long time, resulting in good stability, reduced frequency of medication, improved patient compliance, and reduced patient pain. Compared with free drug at the same concentration, drug delivered via an NP carrier has a much more prominent inhibitory effect on cellular growth, along with prolonged drug release. ${ }^{54}$ Moreover, NPs can be activated by different types of controllable stimulatory factors (such as chemical agents, a magnetic field, light, $\mathrm{pH}$, and heat). ${ }^{55-57}$

In ocular remedies delivered using an appropriate SL NP carrier that can prolong the retention time in the pre-corneal area, the release of levofloxacin and other drugs is sustained and controlled, producing a better curative effect compared with conventional ophthalmic solutions. ${ }^{58,59}$

Combination: Multiple drugs or antimicrobials can be packaged within the same NP, and NPs can be combined with other constructs to improve the agents' antibacterial properties. In this article, two levels of "combination" are described.

On the one hand, when faced with a single type of NP containing multiple antibacterial agents, it is difficult for bacteria to be resistant or to develop resistance because the probability of a cell containing multiple resistance mutations is very small. In addition, the simultaneous combination of different drugs results in higher efficiency due to the joint action of multiple mechanisms.

On the other hand, two or more types of NPs can be used in combination for enhanced antibacterial effects and prevention of resistance. ${ }^{6}$ When used alone, different types of NPs have distinct disadvantages. For example, the disadvantages of liposomes are their short shelf life, poor stability, low encapsulation efficacy, rapid removal by the reticuloendothelial system, cell interactions or adsorption, and intermembrane transfer. The disadvantages of SL NPs are an unpredictable gelation tendency and inherent low incorporation rates. ${ }^{49}$ Hybrid NPs can maximize the strengths while minimizing the weaknesses of the individual types of NPs. For example, studies have shown that superior efficacy of in vivo cellular delivery can be achieved by lipid-polymer hybrid NPs compared with delivery without polymeric NPs or by liposomes. ${ }^{60}$

In addition, a prolonged effective time can be achieved through the "combinatorial" method, which can effectively and significantly reduce the possibility of the development of resistance in bacteria. ${ }^{61}$
The abovementioned advantages may unite in diverse combinations with different emphases in the process of actual application.

\section{Negative side: as a promoter of drug resistance}

With more and more research available, knowledge of the effects of NPs is beginning to develop from a single, positive angle, even as researchers try their best to be unbiased. While most of the studies mentioned earlier have shown evidence that the use of NPs as an antibacterial agent can effectively reduce the rate of resistance, the existence of a "pushing hand" is undeniable under certain experimental conditions, such as "in water along with the proper temperature and $\mathrm{pH}^{\prime} .{ }^{19}$

This phenomenon has been investigated. One study ${ }^{19}$ reported that the conjugative transfer of plasmids (such as RP4, PK2, and pCF10) could be promoted by aluminum NPs, which further resulted in the dissemination of MDR among bacteria not only of the same species but also across genera. The factors related to this promotion are as follows: 1) the extent of damage to the bacterial cell membranes resulting from oxidative stress caused by the aluminum NPs; 2 ) the concentrations of the aluminum NPs and mating cells; 3 ) the suitable environment, including the temperature and $\mathrm{pH}$, which affects the transfer in water; and 4) the selectively promoted expression of specific genes (such as trfAp, trfA, and trbB) that are important for the transfer and replication of RP4 plasmids.

The negative effects also require attention to prevent the promotion of MDR, which may result in further hazards to public health and the environment.

\section{The application of NPs}

Resurgent interest in NPs has been stimulated by the appearance of drug-resistant bacteria and the increasing rate of hospital infection outbreaks. Due to their excellent antimicrobial resistance properties, NPs have been widely used in many fields. Each type of NP has its own advantages and localization. Parameters including the mean particle size, shape, the specific surface area, and surface curvature affect the antibacterial activity and mechanism. In fact, the application of NPs in fighting bacteria has decreased bacterial infection. In the following sections, the antibacterial applications of NPs are discussed in detail.

\section{Antibacterial application of NPs Antibacterial coating of implantable devices}

There are two types of human implantable devices with antimicrobial coatings; the first type is fully implantable 
devices, such as heart valves or dental implants. The antimicrobial coating of cardiovascular apparatuses in particular must have the appropriate blood compatibility to prevent thrombosis. The application of a titanium oxide coating on implants is based on pore morphology, with calcium, silicon, phosphorus, and silver particle enrichment. ${ }^{62}$ The coating inhibits the adhesion and growth of bacteria such as Streptococcus mutans, Streptococcus epidermis, and E. coli and prevents the occurrence of inflammation around the implants. Preliminary biological characterization also indicated that a nanocoating can improve the adhesion and proliferation of osteoblast cell lines. ${ }^{63}$ The other type of device is partially implantable devices, such as catheters, intravenous catheters, or neurosurgical catheters, which are more prone to bacterial colonization, thereby increasing the risk of infection in clinical applications. Specifically, nanopolymers can be used as antibacterial materials to retard the growth of catheter biofilms. ${ }^{64,65} \mathrm{NP}$ coatings on invasive neurosurgical catheters can reduce the risk of bacterial infection and complications, with sustained release of NPs over 6 days significantly reducing the growth of $S$. aureus.

\section{Wound dressings}

Skin is the natural protective barrier of the body, and it not only protects the body from pathogens and foreign bodies but also maintains the dynamic equilibrium of water and electrolytes. Trauma, burns, and several types of chronic skin ulcers can damage skin. A cover, called a dressing, must be used in the process of wound healing to rebuild the barrier function of skin, to accelerate wound healing, and to reduce the risk of wound infection. An ideal dressing would have similar characteristics to skin, such as promoting the proliferation and migration of fibroblasts, accelerating the formation of epithelial tissue, reducing scar formation, and exhibiting certain antibacterial and anti-inflammatory effects. ${ }^{66}$

Many microorganisms can cause wound infections, and these can be divided into two types: 1) Gram-positive bacteria, such as Staphylococcus and Streptococcus, and 2) Gram-negative bacteria, such as E. coli and Klebsiella spp. Chronic infection is often accompanied by infections by multiple bacterial species and antibiotic resistance, but NPs possess broad-spectrum antimicrobial properties that can significantly inhibit bacterial growth and reproduction. The combination of nanosilver and a mixture of poly(vinyl alcohol) and chitosan (CS) has been studied in this context, ${ }^{67}$ and the resulting fiber mat can be used in wound healing. The high specific surface area of nanosilver results in good contact with bacteria, significantly inhibiting their growth and increasing the rate of wound healing.

\section{Bone cement}

Bone cement is a self-curing plastic at room temperature that is composed of polymethyl methacrylate (PMMA) or modified PMMA and methyl methacrylate (MMA). Bone cement is commonly used to fix joint prostheses, such as in knee or hip replacement surgery, by filling the gap between the implant and bone. A previous study ${ }^{68}$ found that the infection rate following total joint replacement surgery was as high as 3\%, and antibiotic-loaded PMMA may decrease the infection rate to $0 \% .{ }^{69}$ However, multiple other studies have shown that bone cement loaded with antibiotics did not significantly reduce infection rates. ${ }^{70,71}$ Therefore, it is still unclear whether the traditional method of loading bone cement with antibiotics effectively reduces the infection rate following arthroplasty. However, the number of resistant bacterial strains is currently increasing, and if effective measures are not taken, incurable infectious diseases and small wounds may lead to death. NPs have a strong killing effect on certain types of antibacterial-resistant bacteria, and this effect has become a research hotspot. ${ }^{17}$ PMMA-based bone cement mixed with Ag NPs significantly reduces the formation of surface biofilms according to the Kirby-Bauer method and the time-kill method; the main mechanism of this Ag NP-PMMA is prevention of bacterial surface colonization. ${ }^{72} \mathrm{~A}$ concentration of nanosilver as low as $0.05 \%$ can significantly reduce the number of arthroplasty surgery-related infections, including methicillin-resistant S. aureus (MRSA), S. aureus, S. epidermidis, and Acinetobacter baumannii infections. ${ }^{73}$ Ag NPs have also been used to replace antibiotics in the development of a promising antibacterial bone cement. ${ }^{74}$

\section{Dental materials}

Plaque is an important ecological environment that allows microbes to settle on the teeth and is the initiating factor for common infectious diseases in the mouth. Many dental materials show improved performance after nanocrystallization. For example, nanodiamond-functionalized amoxicillin in combination with gutta-percha for root canal treatment can eliminate residual bacteria after root canal filling. ${ }^{75}$ In addition, due to the proliferation of bacteria and the reduction in $\mathrm{pH}$ in the course of treatment, orthodontic treatment often leads to the formation of dental plaque chalk, and brackets coated with $\mathrm{CuO}$ and $\mathrm{ZnO}$ NPs can effectively inhibit the growth of $S$. mutans; however, the coatings also affect the appearance of the brackets. ${ }^{76}$

Maxillofacial prostheses placed in a complex external environment containing a variety of flora have been shown to develop biofilms, thereby increasing the incidence of tissue inflammation surrounding the prostheses. The addition of 
nano-titanium dioxide to prostheses resulted in antibacterial effects following light exposure. ${ }^{77}$ The clinical application of antibacterial NPs is further illustrated in Figure 1.

\section{NP-based antibiotic delivery systems}

Osteomyelitis is mainly caused by pyogenic bacteria found in healthy oral flora, although cases of infection caused by fungi are also common. However, bone is typically protected from external pathogens, so the incidence of osteomyelitis is low. The difficulty faced by invasive pathogens in the colonization of bone is directly proportional to the difficulty of introducing antibiotics into the site of infection. The major downsides of conventional antibiotic approaches include 1) the systemic toxicity of antibiotics and 2) the inability of antibiotics to reach an effective concentration at the local site of infection.

The use of NPs can be considered a win-win solution in the quest for simultaneous bactericidal and osteogenic properties. Drug adsorption efficiency is directly proportional to the specific surface area of the adsorbent and inversely proportional to the particle size. Because of their large surface area and functionalization, NPs can be used as transporters to achieve targeted drug delivery. For example, the same effect of extended release can be achieved by compacting antibiotic-loaded calcium phosphate powder under pressure. Moreover, NPs have distinct advantages over other existing medicine carrier systems in terms of reducing the side effects of antibiotics.

In-depth research is being conducted to utilize the biological effects of nanomaterials for the delivery of antibiotics. ${ }^{78-81}$ Gentamicin undergoes controlled release from CS/fucoidan NPs, which renders the NPs into a multiple-function drug delivery system with antibacterial and antioxidant activities that can be used to treat pneumonia. ${ }^{82}$ In addition, CS-coated alginate NPs increase the ability of daptomycin to permeate the limbal epithelium of the eye and also increase its ocular accumulation and effect duration. The key features of a drug delivery system are biodegradability, biocompatibility, controlled drug transport, and delivery to the target tissue. ${ }^{83}$

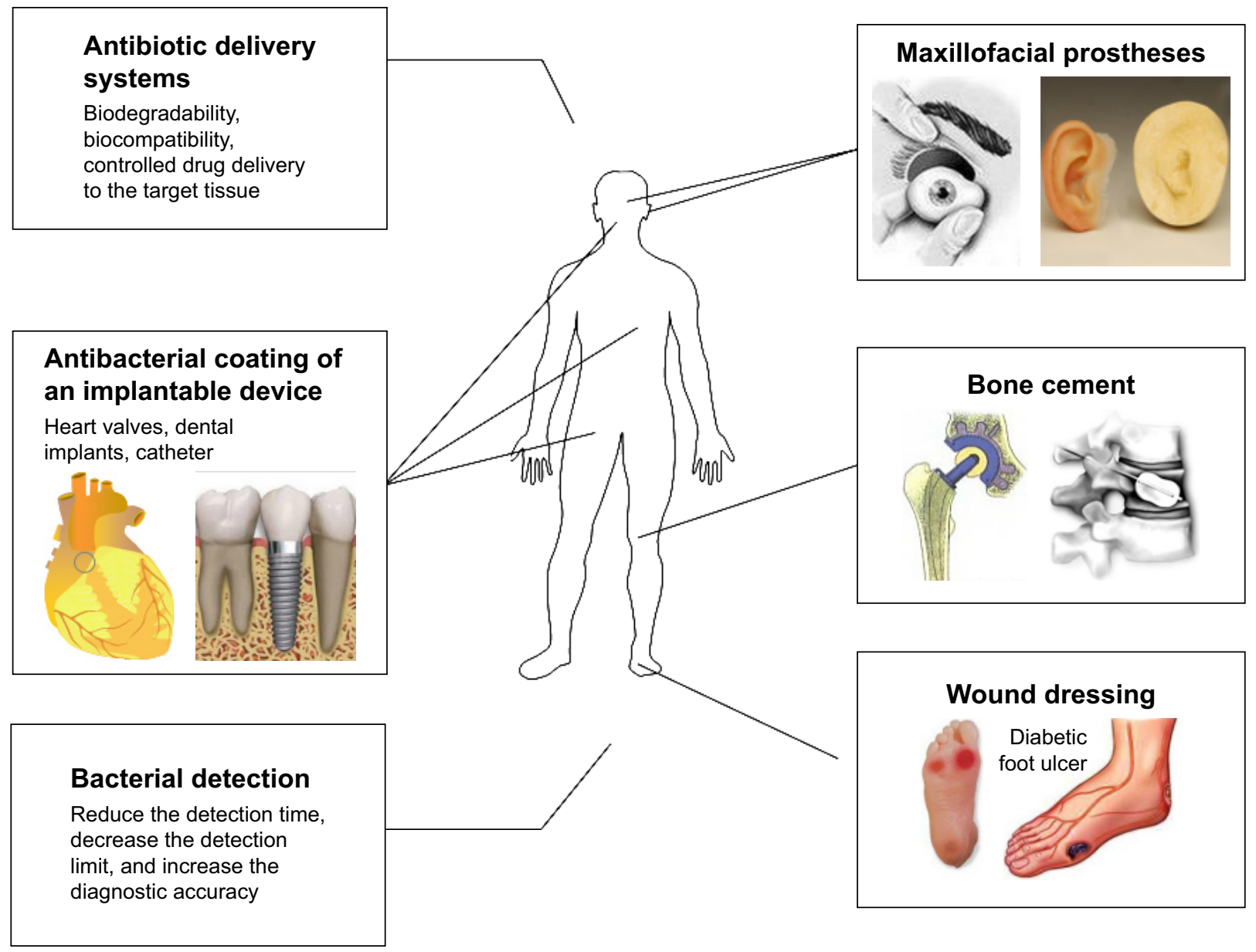

Figure I The antibacterial application of NPs. Abbreviation: NPs, nanoparticles. 


\section{Antibacterial mechanisms of NPs}

The increasing use of NPs in medicine has led to a growing number of studies exploring potential antibacterial mechanisms of NPs. ${ }^{6}$ For example, metal NPs can change the metabolic activity of bacteria ${ }^{84}$ This capacity represents a huge advantage in terms of eliminating bacteria to cure diseases. The ability of NPs to enter biofilms also provides a practical method to inhibit biofilm formation based on the Ag-inhibited expression of genes. ${ }^{85}$

NPs need to be in contact with bacterial cells to achieve their antibacterial function. The accepted forms of contact include electrostatic attraction, ${ }^{86}$ van der Waals forces, ${ }^{87}$ and receptor-ligand ${ }^{88}$ and hydrophobic interactions. ${ }^{89}$ NPs then cross the bacterial membrane and gather along the metabolic pathway, influencing the shape and function of the cell membrane. Thereafter, NPs interact with the bacterial cell's basic components, such as DNA, lysosomes, ribosomes, and enzymes, leading to oxidative stress, heterogeneous alterations, changes in cell membrane permeability, electrolyte balance disorders, enzyme inhibition, protein deactivation, and changes in gene expression. ${ }^{90-92}$ The following mechanisms are the most frequently proposed in current research: oxidative stress, ${ }^{11}$ metal ion release, ${ }^{93}$ and non-oxidative

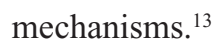

\section{Oxidative stress}

ROS-induced oxidative stress is an important antibacterial mechanism of NPs. ROS is a generic term for molecules and reactive intermediates that have strong positive redox potential, and different types of NPs produce different types of ROS by reducing oxygen molecules. The four ROS types are the superoxide radical $\left(\mathrm{O}_{2}^{-}\right)$, the hydroxyl radical $(\cdot \mathrm{OH})$, hydrogen peroxide $\left(\mathrm{H}_{2} \mathrm{O}_{2}\right)$, and singlet oxygen $\left(\mathrm{O}_{2}\right)$, which exhibit different levels of dynamics and activity. For example, calcium oxide and magnesium oxide NPs can generate $\mathrm{O}_{2}^{-}$, whereas zinc oxide NPs can generate $\mathrm{H}_{2} \mathrm{O}_{2}$ and $\mathrm{OH}$ but not $\mathrm{O}_{2}^{-}$. Meanwhile, copper oxide NPs can produce all four types of reactive oxygen. Studies have indicated that $\mathrm{O}_{2}^{-}$and $\mathrm{H}_{2} \mathrm{O}_{2}$ cause less acute stress reactions and can be neutralized by endogenous antioxidants, such as superoxide enzymes and catalase, whereas $\cdot \mathrm{OH}$ and $\mathrm{O}_{2}$ can lead to acute microbial death. The main causes of ROS production are restructuring, defect sites, and oxygen vacancies in the crystal. ${ }^{94}$ Under normal circumstances, the production and clearance of ROS in bacterial cells are balanced. In contrast, with excessive production of ROS, the redox balance of the cell favors oxidation. This unbalanced state produces oxidative stress, which damages the individual components of bacterial cells. ${ }^{95,96}$
Oxidative stress has been confirmed as a key contributor to changing the permeability of the cell membrane, which can result in bacterial cell membrane damage. ${ }^{97}$ Ansari analysis confirmed that $\mathrm{Al}_{2} \mathrm{O}_{3}$ NPs crossed the cell membrane to become intracellular, and the interaction of the NPs with the cell membrane eventually triggered loss of membrane integrity, most likely due to intracellular oxidative stress. ${ }^{98}$ In the same way, nanosilver ions are used as the center of catalytic activity to activate the oxygen in air or water, leading to the production of hydroxyl radicals and reactive oxygen ions, which prevent the proliferation of bacteria or kill them. ${ }^{91,92} \mathrm{~A}$ growing number of studies have also shown that ROS play a key role in the interaction between DNA and bacterial cells. ${ }^{99}$ Moreover, ROS are beneficial to increasing the gene expression levels of oxidative proteins, which is a key mechanism in bacterial cell apoptosis. ${ }^{100}$ Furthermore, ROS can attack proteins and depress the activity of certain periplasmic enzymes that are essential to maintaining normal morphology and physiological processes in bacterial cells. ${ }^{101}$ NPs can produce ROS by different mechanisms. The photocatalytic hypothesis is the current mainstream view. When metal oxide NPs, such as zinc oxide and titanium oxide, accept light irradiation energy greater than or equal to the band gap, the electrons $(\mathrm{e}-)$ in the valence band are stimulated and transition to the conduction band, resulting in a corresponding hole in the valence band $\left(\mathrm{H}^{+}\right)$and producing highly reactive reactants (electrons and holes) on the surface of and inside the catalytic material. $\mathrm{H}^{+}$adheres to the surface of $\mathrm{ZnO}$ after interaction with $\mathrm{H}_{2} \mathrm{O}$ or $\mathrm{OH}^{-}$, which is then oxidized to the hydroxyl radical $(\cdot \mathrm{OH})$. Similarly, after electronic interaction with $\mathrm{O}_{2}$ and adherence to the surface of $\mathrm{ZnO}$, the hydroxyl radical is reduced to the superoxide radical $\left(\mathrm{O}_{2}^{-}\right)$. The generation of ROS degrades the active components that are responsible for maintaining the normal morphological and physiological functions of the microorganism. ${ }^{102}$ In particular, $\mathrm{TiO}_{2}$ NPs generate electron-hole pairs after absorbing light. ${ }^{103}$ Electron-hole pairs react with water and air on the surface of the NPs to produce highly chemically active ROS that attack intracellular organic matter in bacteria. As another example, zinc ${ }^{104}$ is activated under ultraviolet (UV) and visible light, resulting in highly reactive ROS. Negatively charged superoxide and hydroxyl radicals can be maintained on the cell surface and do not penetrate into the intracellular regions of bacteria, whereas $\mathrm{H}_{2} \mathrm{O}_{2}$ can pass through the cell membrane. Scanning electron microscopy (SEM) revealed that zinc oxide NPs transformed the spiral shape of most Campylobacter jejuni cells into a spherical shape, causing a degree of cell damage and leakage. In addition, quantitative real-time polymerase chain reaction (RT-PCR) showed that 
ROS increased the expression levels of two oxidative stress genes (Kat A and Ahp C) and a general stress response gene (Dna K) by 52, 7, and 17 times, respectively. Furthermore, ultrasonic activation also can induce ROS formation. Zinc oxide NPs can split $\mathrm{H}_{2} \mathrm{O}$ into $\mathrm{H}^{+}$and can react with dissolved oxygen to generate $\mathrm{H}_{2} \mathrm{O}_{2}$ in an environment containing water and oxygen. These ROS then penetrate the cell membrane to kill bacteria. Ultrasonic treatment of polymer NPs and colony-forming units can dissociate the NPs and promote their penetration through the cell membrane. In addition, antimicrobial metal ions are rapidly released from the surface to inhibit the proliferation of bacteria under ultrasonic conditions, which may be due to the increased rates of transport of bacterial oxygen, nutrients, and waste caused by ultrasound. ${ }^{105}$ However, a previous study ${ }^{106}$ showed that NPs also have antibacterial activity in the dark. $\mathrm{ZnO}$ produced minimal amounts of $\mathrm{OH}$, which is the main antimicrobial substance produced by zinc oxide when stimulated by light. Oxygen vacancies located on the surface of $\mathrm{ZnO}$ play a significant role in producing $\mathrm{H}_{2} \mathrm{O}_{2}$. In heterogeneous catalysts, the catalytic activity of metal oxides depends on the density of the active site. Solid defects are often considered as the active sites of heterogeneous catalysis. The antibacterial activity of $\mathrm{ZnO}$ can be affected by the size of the zinc oxide crystals, the lattice constant, and the direction; the dominant factor is the $V_{0}$ surface concentration on zinc oxide.

\section{Dissolved metal ions}

Metal ions are slowly released from metal oxide and are absorbed through the cell membrane, followed by direct interaction with the functional groups of proteins and nucleic acids, such as mercapto (-SH), amino $(-\mathrm{NH})$, and carboxyl $(-\mathrm{COOH})$ groups, damaging enzyme activity, changing the cell structure, affecting the normal physiological processes, and ultimately inhibiting the microorganism. However, the impact of metal ions on the $\mathrm{pH}$ inside lipid vesicles is small during the antibacterial process of metal oxide suspension and has weak antimicrobial activity. Therefore, dissolved metal ions are not the main antimicrobial mechanism of metal oxide NPs. ${ }^{102}$ Similarly, a study showed that superparamagnetic iron oxide interacts with microbial cells by directly penetrating the cell membrane and interfering in the transfer of transmembrane electrons. In addition, heavy metal ions can indirectly act as carriers of antimicrobial substances. ${ }^{107}$

\section{Non-oxidative mechanisms}

Certain scholars have used electron spin resonance, liquid chromatography-mass spectrometry, proteomics tools, transmission electron microscopy (TEM), Fourier transform infrared (FTIR) analysis, and flat cultivation to study the antibacterial mechanisms of an $\mathrm{MgO}$ nanomaterial. Three types of MgO NPs have good antibacterial effects on E. coli under UV light, natural light, or complete darkness. These antibacterial mechanisms of NPs are unrelated to the membrane lipid peroxidation caused by oxidative stress, based on the following three points: 1) when the bacterial cell membrane is broken and surface pores are clearly visible, $\mathrm{MgO}$ NPs are not observed in the cell. Moreover, no excessive $\mathrm{Mg}$ ions are visible in energy-dispersive X-ray spectroscopy spectra. Thus, the inhibitory effect of $\mathrm{MgO}$ damages the cell membrane. 2) Only one type of $\mathrm{MgO} \mathrm{NP}$ can detect small amounts of ROS; the other two cannot. 3) Lipopolysaccharide (LPS) and phosphatidylethanolamine (PE) in the cell wall are not significantly changed by MgO NP treatment, which indicates that $\mathrm{MgO}$ does not cause lipid peroxidation. In addition, the amount of ROS-associated protein in the cell is not increased, but many critical cellular metabolic processes related to proteins, including amino acid metabolism, carbohydrate metabolism, energy metabolism, and nucleotide metabolism, are significantly reduced. ${ }^{13}$

\section{Antibacterial activity of NPs}

\section{The interaction of NPs with the cell barrier}

Cell walls and membranes are important defensive barriers for bacterial resistance to the external environment. In particular, the bacterial cell wall plays an important role in maintaining the bacterium's natural shape. The components of the cell membrane produce different adsorption pathways for NPs and Gram-positive and Gram-negative bacteria. ${ }^{108}$ LPS is a unique structure of the cell wall of Gram-negative bacteria that provides a negatively charged region that attracts NPs. In contrast, teichoic acid is only expressed in the cell wall of Gram-positive bacteria, so NPs are distributed along the molecular chain of phosphate, preventing their aggregation. Many studies have shown that NPs have greater activity against Gram-positive bacteria than against Gram-negative bacteria, because the cell wall of Gram-negative bacteria is composed of LPS, lipoproteins, and phospholipids, which form a penetration barrier that allows the entrance of only macromolecules. In contrast, the cell wall of Gram-positive bacteria includes a thin layer of peptidoglycan as well as teichoic acid and abundant pores that allow foreign molecules to penetrate, resulting in cell membrane damage and cell death. In addition, compared with Gram-negative bacteria, Gram-positive bacteria have a high negative charge on the cell wall surface, which can attract NPs. ${ }^{109}$ In one study, a hydroxyapatite whisker/ 
nano-zinc oxide (HAPw/n-ZnO) composite had a stronger antimicrobial effect on S. mutans, Candida albicans, and $S$. aureus than on E. coli. The mechanism through which NPs cause bacterial death is dependent on the components and structure of the bacterial cell. Further explanations of the activity noted in the abovementioned study were given: 1) the antimicrobial action of $\mathrm{ZnO}$ is dependent on the specific bacterial cell composition, which might be improved for Gram-positive bacteria. 2) Certain components peculiar to Gram-negative bacteria, such as LPS, can prevent the adhesion of ZnO NPs to the bacterial cell barrier and regulate the flow of ions in and out of the bacterial cell membrane. 3) The thickness of the bacterial cell wall in Gram-negative bacteria affects the antibacterial function of NPs. ${ }^{102}$ Certain researchers similarly believe that the structure of bacteria can affect the antimicrobial activity of NPs. Hyldgaard et $\mathrm{al}^{110}$ showed that the phospholipid head groups of the LPS membranes in E. coli interact with $\varepsilon$-poly-L-lysine through electrostatic attraction, damaging the cell membrane. However, Listeria innocua film contains lysine-derived phospholipids, is amphoteric, and does not have a sufficiently strong net negative charge to attract cationic peptides; therefore, the cell membrane of $L$. innocua has lower permeability than that of E. coli. In another study, Wehling et al ${ }^{111}$ investigated the antibacterial activity of nanodiamonds in various surface structures with different reactive groups and found that these nanomaterials can form covalent bonds with adjacent proteins and molecules on cell walls. Coupling with intracellular components could further restrain key enzymes and proteins, causing a disorder of the bacterial metabolism and, finally, cell death. Figure 2 shows that nanodiamonds can destroy a bacterial barrier to perform their antibacterial function.

Foster et al ${ }^{112}$ confirmed that titanium dioxide NPs can adhere to the surface of bacterial cells to produce ROS and damage the composition and structure of the cell membrane, thereby interfering with the function of the cell membrane and causing leakage of cellular contents, resulting in bacterial death. SEM has ${ }^{113}$ shown that treatment with $\mathrm{TiO}_{2} \mathrm{NPs}$ increases the bacterial cell volume, causes honeycomb changes in the cell membrane, and causes cytoplasmic leakage. The surface of a bacterial cell has many pits, and bits of cell debris have been observed after $\mathrm{n}-\mathrm{ZnO}$ treatment, ${ }^{101}$ resulting in reduced enzymatic activity and eventual bacterial death. Iron can also cause bacterial cell decomposition, ${ }^{114}$ and NPs can cause bacterial cells to aggregate, resulting in inactivation due to compression. ${ }^{115}$ Physical damage of bacterial membranes is the most important mechanism of the antibacterial activity of graphene. Tu et al ${ }^{116}$ investigated the antibacterial molecular mechanisms of graphene nanosheets against E. coli. Based on molecular dynamics simulations revealing the atomic details of the process by which graphene nanosheets induce the degradation of the cell membrane, the researchers concluded that destructive extraction of phospholipid molecules from the cell membrane by graphene nanosheets led to bacterial inactivation. Similar results were obtained by Akhavan and Ghaderi, ${ }^{117}$ who analyzed the interaction of graphene nanosheets with the cell membrane of bacteria. Specifically, the graphene was completely wetted in water by membrane lipids, and the dispersive adhesion between the graphene and the lipids played a dominant role during extraction.

In addition, Joost et $\mathrm{al}^{113}$ analyzed bacterial cell chemical structure and membrane changes using X-ray photoelectron spectroscopy after saturated fatty acid and unsaturated fatty acid oxidation and decomposition. Joost et al also determined malondialdehyde (MDA) content (MDA is the most important product of membrane lipid peroxidation), and the results showed that NPs can cause oxidative decomposition of the bacterial membrane. Direct contact between titanium oxide and the bacterial cell increases membrane permeability, but the effects are reversible at this stage. ${ }^{118}$ The cell wall is then gradually destroyed, and small molecules, such as ions and other substances, begin to leak from the cell; at this stage, the damage is irreversible. However, because peptidoglycan is highly cross-linked, the damage at this stage is not apparent. The cytoplasmic membrane is then projected into the surrounding medium through the degradation zone of peptidoglycan, leading to membrane damage and allowing higher molecular weight components, such as proteins, to cross the membrane. The final stage is cell degradation. ${ }^{112}$ Aluminum oxide NPs stimulate the formation of irregularly shaped pits and perforations in the cell membrane, which then interact with biological molecules in the cell. Attenuated total reflection (ATR)-FTIR analysis revealed that aluminum oxide NPs can interact with LPS and La-PE. Infrared (IR) analysis indicated that LPS can interact with $\mathrm{Al}_{2} \mathrm{O}_{3}$ NPs through hydrogen bonding and ligand exchange. Structural changes in the phospholipid lead to the loss of parent molecules, destruction of the cell membrane, and cytoplasmic leakage. ${ }^{119}$

One of the foremost functions of the cell membrane is in the respiratory activity of bacteria. Studies have reported that NPs disrupt the respiratory activity of the bacterial cell membrane, which can be analyzed by detecting the uptake of $\mathrm{O}_{2}$ or the reduction in 2,3,5-triphenyltetrazolium chloride (TTC). ${ }^{120}$ Nanosilver ions have been shown to inhibit the 
growth of E. coli by causing cell wall pits, increasing membrane permeability and inactivating the respiratory chain. ${ }^{121}$ In addition, the potential of the bacterial cell membrane plays an important role in cell communication, which has a close relationship with apoptosis. For example, the disruptive effect of $\mathrm{TiO}_{2} \mathrm{NPs}$ on the potential of the bacterial cell membrane was measured by fluorescence microscopy, ${ }^{122}$ and changes in the fluorescence intensity of the cytoplasm were observed when altering the potential of the cell membrane.

\section{The penetrating mechanism of NPs}

Diffusion: NPs introduce ROS into bacteria by diffusion. Pan fabricated graphene oxide-iron oxide NPs by the
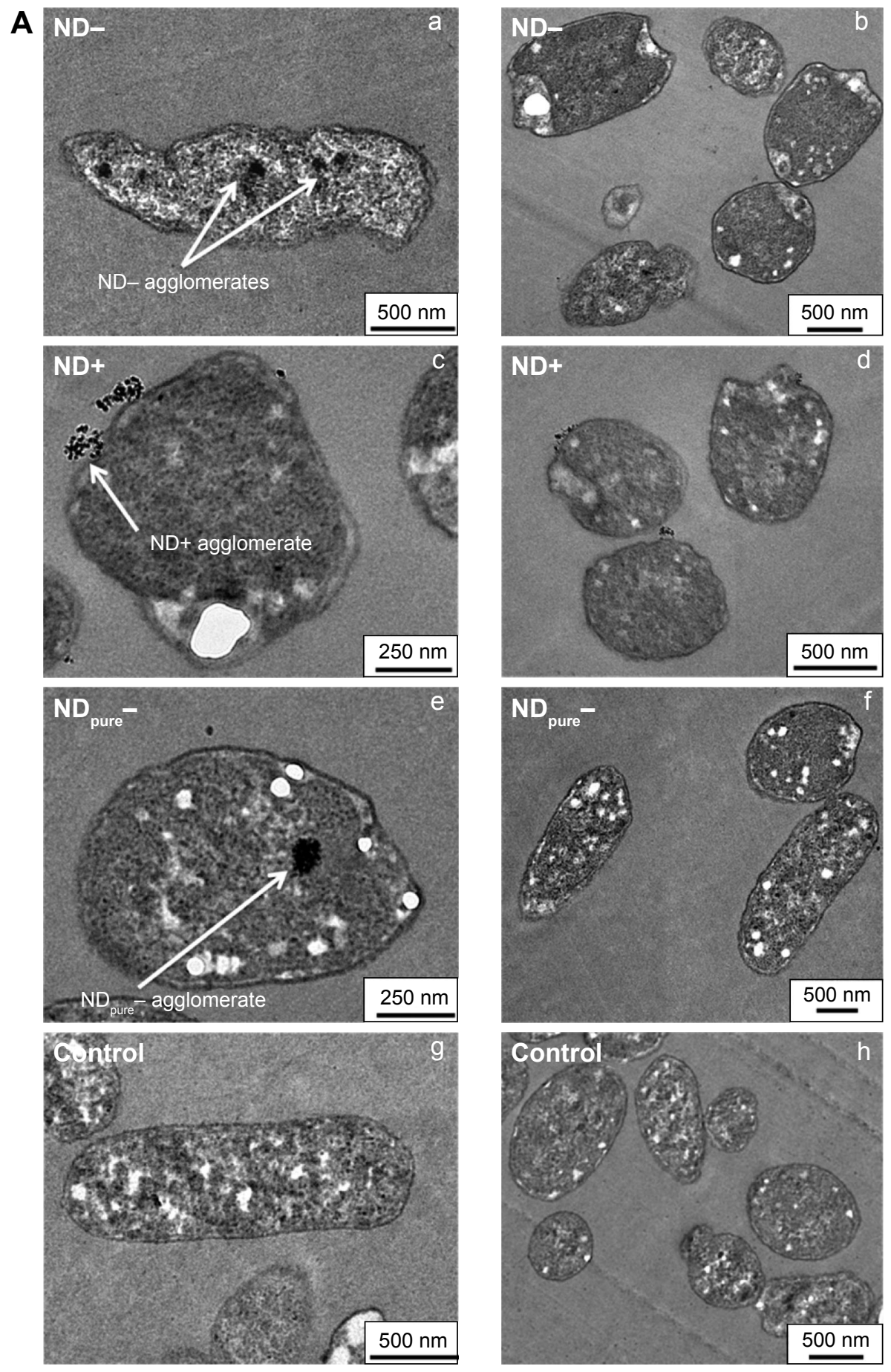

Figure 2 (Continued) 
B

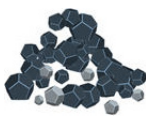

Purified ND (G01 grade)

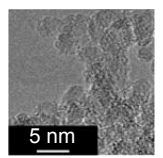

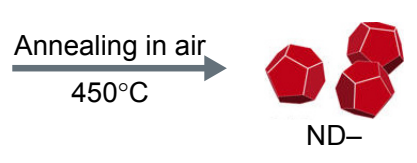
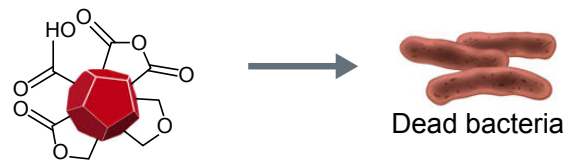

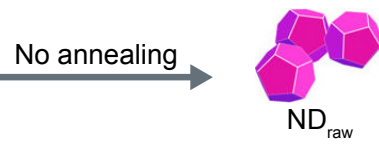

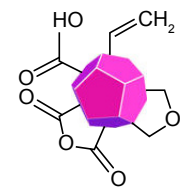

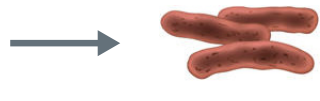

No annealing, no ultrasonication

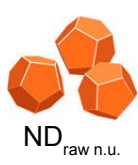

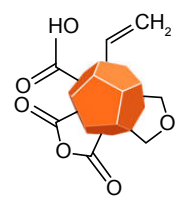
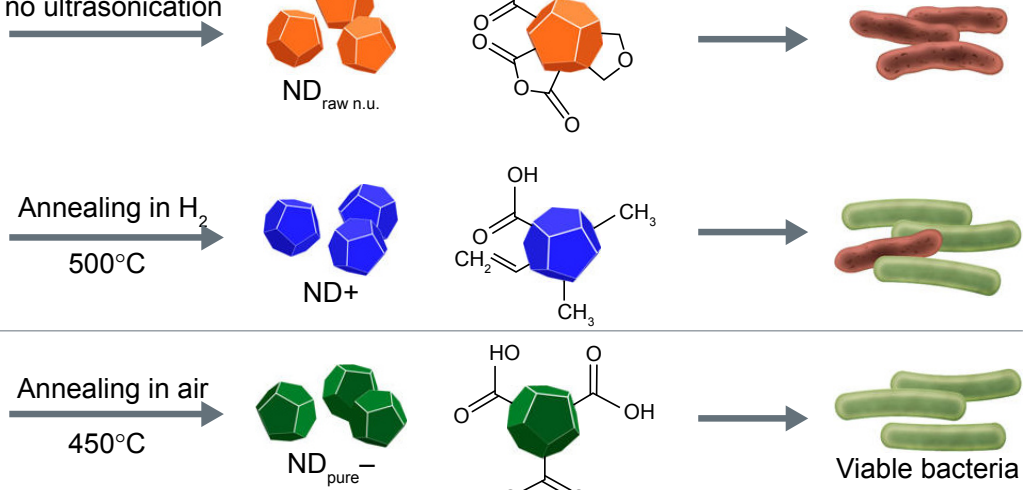<smiles>O=C(O)C1CC2C(C(=O)O)CC1C2C(=O)O</smiles>
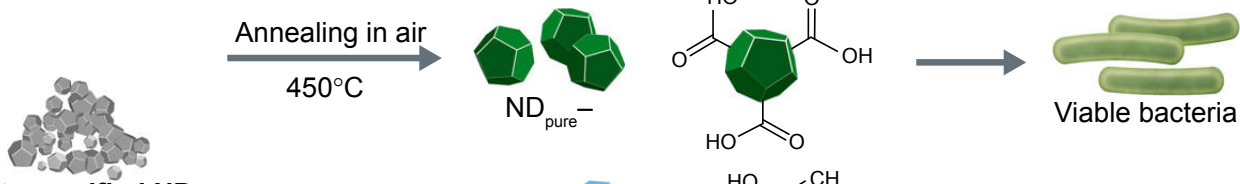

Extra-purified ND

(G02 grade)
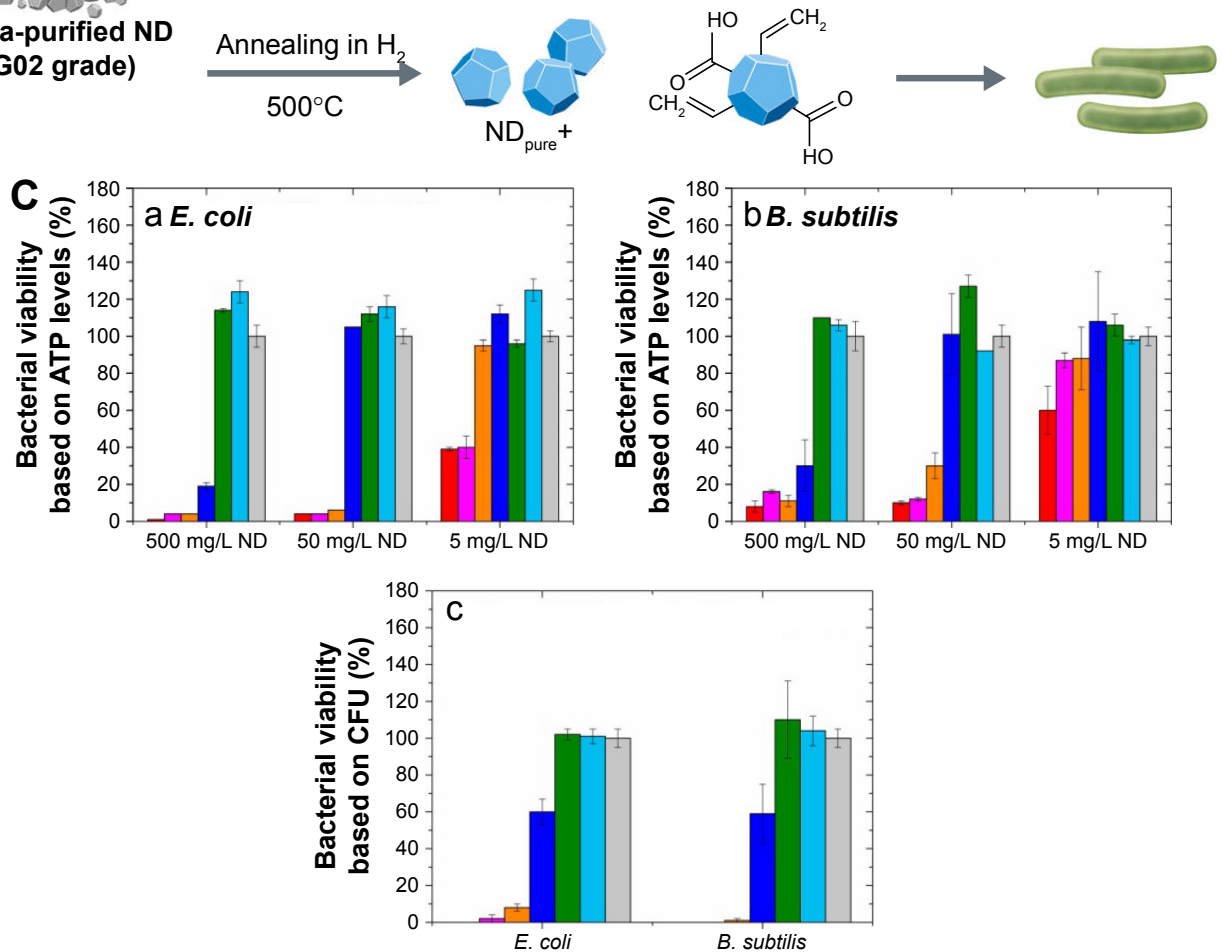

ND- ND $_{\text {raw }} \square \mathrm{ND}_{\text {raw n.u. }} \quad \mathrm{ND}+\mathrm{ND}_{\text {pure }}-\mathrm{ND}_{\text {pure }}+\quad$ Control

Figure 2 Bactericidal activity of NDs.

Notes: (A) TEM images indicate that, at sublethal ND concentrations of $0.5 \mathrm{mg} / \mathrm{L}$, ND- is incorporated into E. coli cells and seems to deform the cellular shape (a, b); ND+ seems mainly to bind to cellular surface structures (c, d); Similar to ND-, agglomerates of negatively charged $\mathrm{ND}_{\text {pure }}$ - are also found inside the cells, but they do not alter bacterial morphology (e, f); showing similar cell shapes to the ND-free control of $E$. coli (g, h). (B) Grades and pretreatments of NDs: a, negatively charged ND- and ND ${ }_{\text {raw }}$ NDD raw n.u were shown to exhibit strong antibacterial properties under aqueous conditions, while ND+ caused bacterial death only at high ND concentrations; b, ND , independent of their charge, did not show any bactericidal effects. (C) Antibacterial activity of NDs on E. coli and B. subtilis. (a,b) Negatively charged ND- and ND raw $/ N_{\text {raw nu. }}$ strongly decreased bacterial viability measured by ATP levels in 15 min, while positively charged ND+ decrease ATP levels only at the highest ND concentrations for Gram-negative E. coli (a) and Gram-positive B. subtilis (b); (c) After incubation with $500 \mathrm{mg} / \mathrm{L}$ NDs, the determination of colony-forming units for $E$. coli and B. subtilis led to similar trends to the measurement of ATP, indicating that ND- and $\mathrm{ND}_{\text {raw }} / \mathrm{ND}_{\text {raw n.u. }}$ are very effective at inhibiting bacterial growth, while positively charged ND+ are less bactericidal. Reprinted with permission from Wehling J, Dringen R, Zare R, Mass M, Rezwan K. Bactericidal activity of partially oxidized nanodiamonds. ACS Nano. 20I4;8(6):6475-6483. Copyright 20I4 American Chemical Society."'I Abbreviations: B. subtilis, Bacillus subtilis; CFU, colony-forming unit; E. coli, Escherichia coli; ND, nanodiamond; TEM, transmission electron microscopy; n.u, no ultrasonication. 
chemical deposition of $\mathrm{Fe}(2+) / \mathrm{Fe}(3+)$ ions on nanosheets of rGO in aqueous ammonia. The combined materials showed maximum antibacterial activity due to the generation of large amounts of hydroxyl radicals and diffusion into bacterial cells, which inactivated MRSA. ${ }^{123}$ Zhang et al ${ }^{124}$ examined the ROS generation mechanism of silver (Ag), gold ( $\mathrm{Au}$ ), nickel (Ni), and silicon ( $\mathrm{Si}$ ) NPs in aqueous suspension under UV irradiation $(365 \mathrm{~nm})$. The result showed that Ag NPs generated superoxide and hydroxyl radicals, whereas Au NPs, Ni NPs, and Si NPs generated only singlet oxygen, which entered cells to produce an antibacterial effect. The diffusion coefficient is the same as that of oxygen, or $\sim 10^{5} \mathrm{~cm}^{2} / \mathrm{s}$. Taking into account the thickness of the cell wall and membrane of E. coli, the diffusion time is $\sim 107 \mathrm{~s}$, and the average lifetime of ROS is $10^{5}-10^{6} \mathrm{~s}$. Therefore, ROS persist for a sufficient amount of time to diffuse into bacterial cells. Hydrogen peroxide and hydroxyl radicals can more easily penetrate cell membranes than the superoxide radical can. In addition to the abovementioned information, Mukha et al ${ }^{125}$ have shown that Ag NPs of $<10 \mathrm{~nm}$ can pass through the pores in the cell membrane, thereby allowing penetration of microbial cells. Therefore, the high antimicrobial activity of the synthesized Ag NPs is provided by a main parameter: size.

Adsorption: The metal ions of NPs are released into the surrounding media and bind with the negatively charged functional groups of the bacterial cell membrane, such as carboxyl and phosphate groups, in a process known as biosorption. Different metal ions have different sites of activity; for example, zinc ions can bind with high affinity to the - $\mathrm{SH}$ groups of proteins. The ordered and closely spaced cell membranes become confused and dispersed, destroying their inherent function and leading to bacterial death. ${ }^{101}$ Silver ion NPs $\left(\mathrm{Ag}^{+} \mathrm{NPs}\right)$ are firmly adsorbed on the cell membrane, which is reliant on Coulomb gravity, leading to protein coagulation. ${ }^{14}$ Similarly, a study showed that the signs of surface charges of Au NPs significantly affect the adsorption of NPs to membranes and that the electric features of the bilayer are also important. ${ }^{126}$

\section{NPs inhibit the synthesis of bacterial proteins and DNA}

In recent years, the interference of NPs with bacterial protein synthesis has gradually attracted the attention of researchers. Su et al ${ }^{127}$ investigated the influence of $\mathrm{CuO} \mathrm{NPs}$ on bacterial denitrification by causing a significant alteration of the expression of key proteins. After entering cells, proteomic bioinformatics analysis showed that $\mathrm{CuO}$ NPs caused regulation of proteins involved in nitrogen metabolism, electron transfer, and substance transport. Figure 3 shows the interaction network of the differential protein expression induced by $\mathrm{CuO}$ NPs. Yamanaka et $\mathrm{al}^{128}$ studied the bactericidal action of Ag NPs against $E$. coli, serving as a model microorganism, via energy-filtering TEM (EFTEM), twodimensional electrophoresis (2-DE), and matrix-assisted laser desorption ionization-time-of-flight MS (MALDI-TOF MS). The results indicated that the expression of a ribosomal subunit protein as well as that of certain other enzymes and proteins is affected by silver ions. ${ }^{91}$ Similarly, Cui et al ${ }^{129}$ examined the antibacterial mechanism of action of Au NPs via transcriptomic and proteomic methods. They found that Au NPs exert antibacterial activity predominantly in two manners: one is prevention of the combination of a ribosomal subunit with tRNA and the other is collapse of the membrane potential, restraining ATPase activities to reduce the ATP level.

$\mathrm{TiO}_{2}$ NPs allow bacterial DNA compression, degeneration, and fragmentation, thereby reducing the physiological activity of genes. ${ }^{115}$ The affinity and binding mode of nanotitanium dioxide and DNA were predicted by molecular docking, which indicated that $\mathrm{TiO}_{2}$ NPs targeted DNA rich in G-C. ${ }^{130}$ In addition, whole-genome analysis can be used to characterize the molecular mechanisms of bacterial apoptosis. Researchers used this technique to analyze the mechanism of NP action against E. coli DNA. ${ }^{131}$ The study showed that mutant genes are concentrated in 10 areas of the bacterial genome, including gene expression, the activity of the molecular structure, the composition of the ribosome, and the modification of RNA. Another mechanism regulating gene expression that is involved in the bactericidal action of $\mathrm{Ag}$ NPs was reported by Nagy et al. ${ }^{12}$ The Ag NPs specifically showed satisfactory sterilization activity against $E$. coli and inhibited the growth of S. aureus and E. coli. The antibacterial activity of the Ag NPs involved a species-specific mechanism of upregulation of several antioxidant genes as well as genes coding for metal transport, metal reduction, and ATPase pumps. Therefore, the antibacterial mechanism of Ag NPs is related to the exhaustion of antioxidant capacity. In addition, the interactions of gold-superparamagnetic iron oxide NPs with bacterial proteins through a strong affinity for disulfide bonds were analyzed and were found to affect the metabolism and redox systems of bacterial cells. In addition, the NPs were found to attack the potential protein fucoidan to disrupt the integrity of the cell membrane, which is an important factor in maintaining cell morphology and controlling the transport of ions and molecules across the membrane. ${ }^{132}$ Many studies 


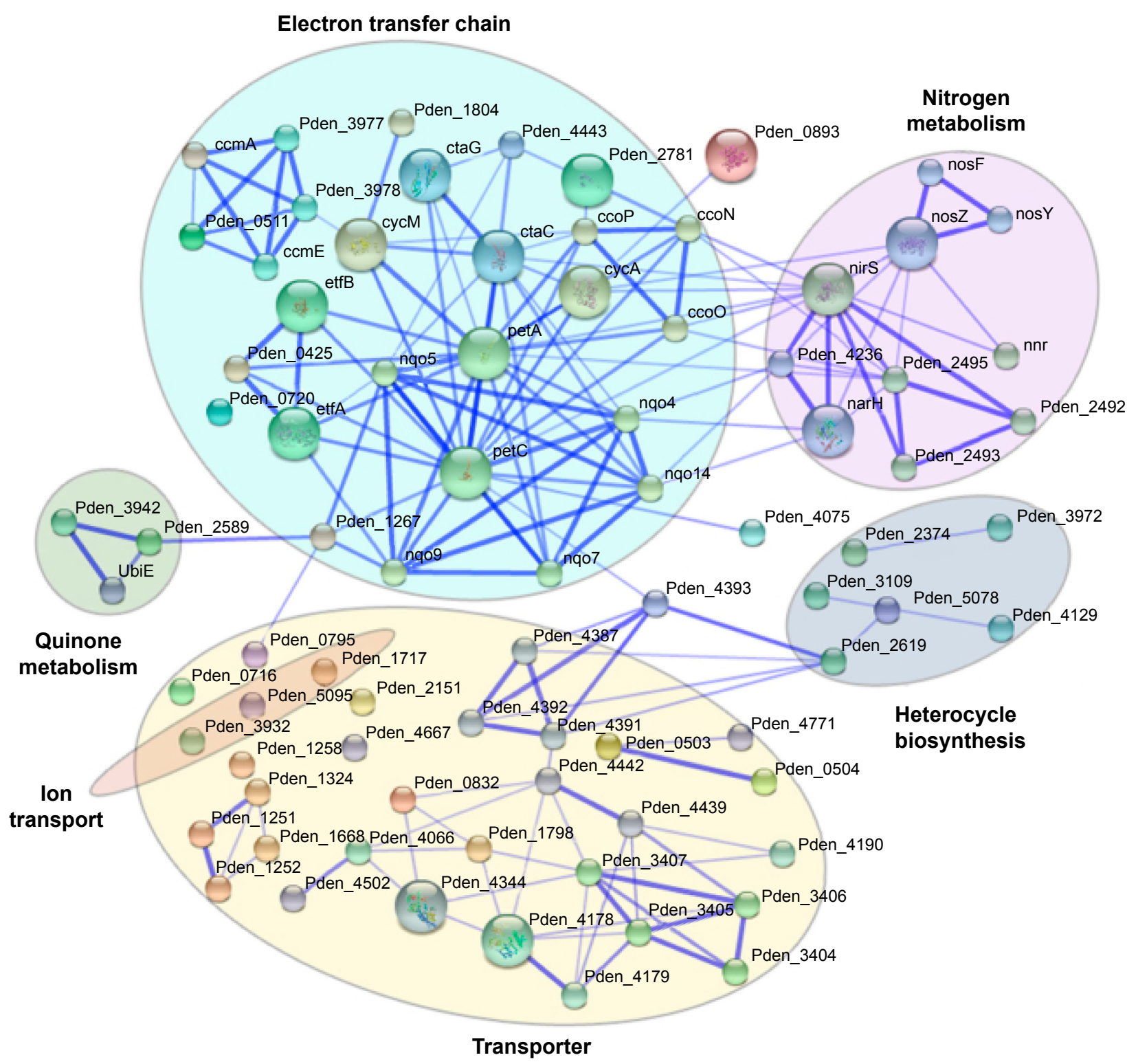

Figure 3 The interaction network of differential proteins induced by CuO NPs.

Notes: The network was created by the STRING algorithm, and strong interactions are represented by thicker lines. Reprinted from Su Y, Zheng X, Chen Y, Li M, Liu K. Alteration of intracellular protein expressions as a key mechanism of the deterioration of bacterial denitrification caused by copper oxide nanoparticles. Sci Rep. $2015 ; 5: 15824 .{ }^{127}$ Abbreviation: NPs, nanoparticles.

have demonstrated that iron can produce ROS, which interfere with electron transport during the oxidation of bacterial nicotinamide adenine dinucleotide. ${ }^{7,133,134}$ In addition, superparamagnetic iron oxide can damage macromolecules, including DNA, lipids, and proteins, through the Fenton reaction, leading to bacterial death. Iron increases the formation of ROS through oxidative stress and stimulates the electron transport chain to produce superoxide $\left(\mathrm{O}_{2}^{-}\right)$, which damages the iron clusters. ${ }^{135}$ Therefore, more divalent iron participates in the oxidation Fenton reaction, leading to the formation of hydroxyl radicals $(\cdot \mathrm{OH})$ and promoting the death of residual bacteria through the catabolism of the carbon source and the generation of nicotinamide adenine dinucleotide. The intake of superparamagnetic iron may also increase simultaneously because of functionalized polycarboxylate.

\section{NPs regulate the expression of metabolic genes}

The processes of normal bacterial metabolism play a major role in maintaining the growth and reproduction of bacteria and can also cause disease. Disturbances in bacterial metabolism cause damage to the bacterial cell membrane and produce oxidative stress, ultimately leading to bacterial cell death.

Bacterial metabolic pathways are not isolated, but rather are integrated into the complex activity of living cells. For example, the glucose metabolism of $S$. mutans is 
an important mechanism that causes dental caries, and Fusobacterium nucleatum can utilize the metabolites of amino acids, such as butyric acid, which affects the progression of periodontal disease. Thus, purposeful alteration of the metabolic activity of bacteria can be used to regulate bacterial cell pathogenicity. Various mechanisms have been proposed for the effects of nanomaterials on bacterial metabolism, including a reactive oxygen mechanism and a metal ion dissolution mechanism. ${ }^{101,102}$ Liquid hue spectrum analysis showed that magnesium oxide $\mathrm{NPs}^{13}$ can alter the expression of many metabolic proteins, including the upregulation of a weak thiamine ester-binding protein and riboflavin metabolic protein and the downregulation of a protein mapped to the critical path of bacterial cell metabolism, resulting in a reduction in cellular metabolic activity, which suggests that NPs regulate the metabolic processes of bacteria by acting on target proteins. Copper oxide NPs can regulate the expression of proteins related to bacterial nitrogen metabolism and significantly inhibit the activity of nitrate reductase and nitrite reductase. ${ }^{127}$

Moreover, considerable evidence has demonstrated that titanium dioxide affects the adhesion rate of bacteria and the formation of biofilms. ${ }^{96,136} \mathrm{NPs}$ can also affect the metabolite levels of bacterial communities. ${ }^{137}$ Bacterial metabolism is an important activity of biofilms: D-alanine metabolism is essential to the formation and growth of $S$. mutans biofilm. ${ }^{138}$ Therefore, we hypothesized that nano-titanium dioxide inhibits the formation of biofilms, which may in turn influence the metabolism of biofilms. Generally, NPs can attack bacteria cells through multiple mechanisms, as reviewed in the following sections (Figure 4).

\section{NPs inhibit the formation of bacterial biofilms}

The structure of biofilms makes bacteria very resistant to foreign chemicals. Earlier reports demonstrated that NPs interfere with biofilm integrity by interacting with EPSs. ${ }^{139}$ Ag NPs inhibit the production of EPSs, which further leads to action against the biofilms of drug-resistant strains of E. coli and Klebsiella pneumoniae. ${ }^{140}$ It was also observed that when a biofilm composed of $B$. subtilis grows to a certain extent, the edge of the biofilm will periodically stop growing so that nutrients can flow into the center of the biofilm. In this way, the bacteria in the center not only can survive but also can resist foreign substances. ${ }^{141}$ However, much evidence ${ }^{96,139}$ shows that NPs can affect the rates of bacterial adhesion and biofilm formation, but the

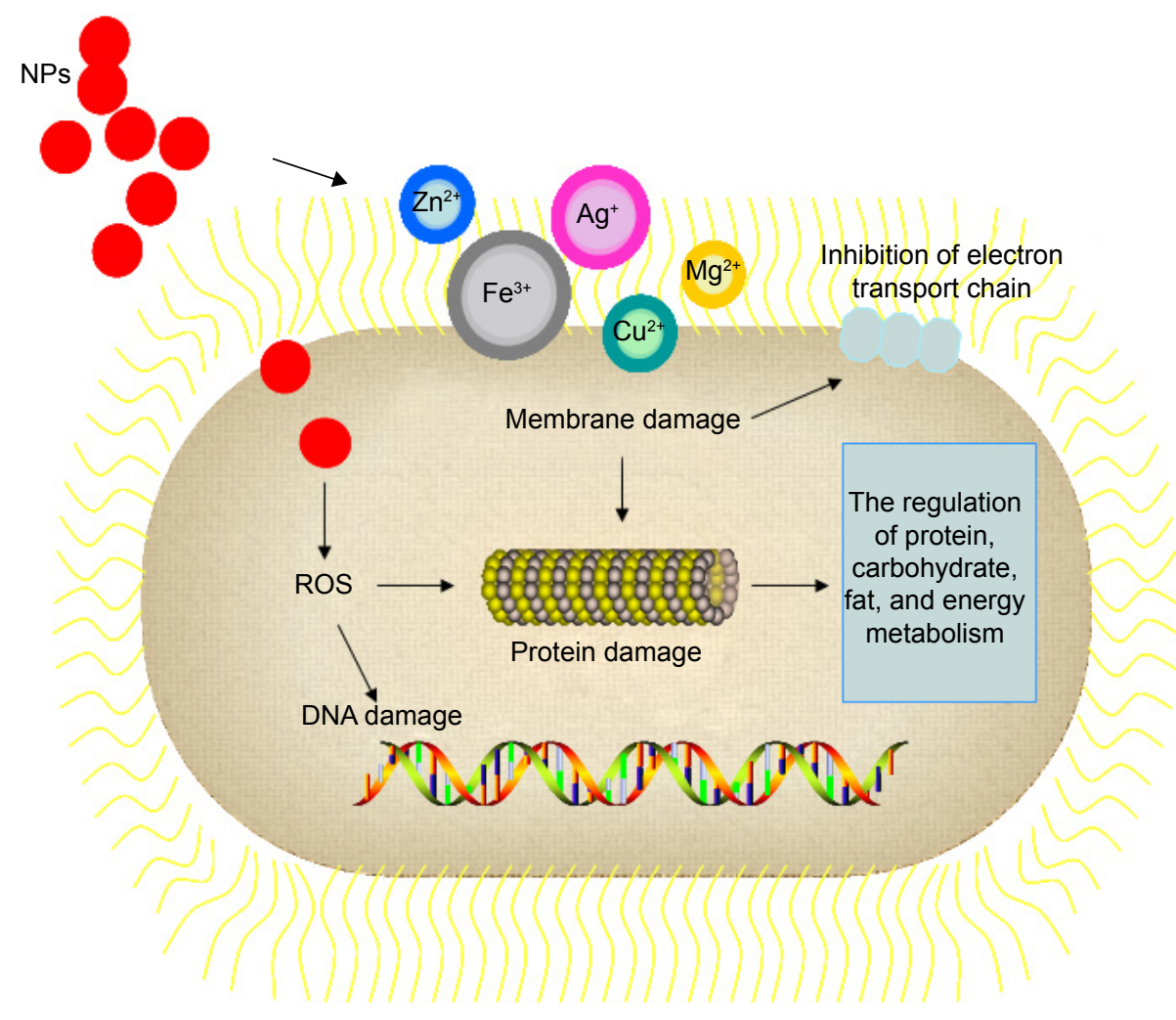

Figure 4 Mechanisms of NP action in bacteria cells.

Notes: NPs can attack bacteria cell through multiple mechanisms: the formation of ROS leading to membrane, protein, and DNA damage; direct interaction occurs with cell membrane because some metal-based NPs can generate metal ion via dissolving, for example, inhibition of electron transport chain; and the regulation of bacterial metabolic processes.

Abbreviations: NPs, nanoparticles; ROS, reactive oxygen species. 
specific mechanism is not yet fully understood. Mohanty developed Ag NPs using silver nitrate $\left(\mathrm{AgNO}_{3}\right)$, and these Ag NPs exhibited activity against bacterial biofilms. ${ }^{142}$ Pan et $a^{137}$ showed that NPs can affect the metabolic level of bacterial communities. Bacterial metabolism is an important activity for biofilms; for instance, D-alanine metabolism is essential for the formation and growth of Streptococcus. ${ }^{138}$ In addition, Lundberg et al ${ }^{143}$ confirmed that the long-distance electrical signal conduction of bacteria in a biofilm is carried out by potassium ion channels. Moreover, diffusion of potassium ions coordinates the metabolic activities of bacteria inside and outside the biofilm. It has been shown that Mg NPs can adhere to and diffuse into biofilms, and that this leads to disruption of the membrane potential, enhanced lipid peroxidation, and DNA binding. Disorder in the normal functioning of these processes decreases the ability of bacteria to form biofilms. ${ }^{144}$ However, studies have shown that NPs can act on the ion channels in bacterial biofilms, thereby regulating the metabolic activity of bacteria. Salem et al ${ }^{145}$ showed that the amounts of Ag NPs and ZnO NPs necessary for growth inhibition (minimal inhibitory concentration assay) and for inhibition of metabolic activity (INT assay) were nearly equal. The result suggested that the dominant antimicrobial targets of the NPs are the metabolic pathways of bacteria. Hence, the mechanism of inhibition of NPs of the formation of bacterial biofilms is related to the regulation of bacterial metabolism.

\section{Crucial factors affecting the antibacterial mechanisms of metal NPs}

The physicochemical properties of NPs include their size, charge, zeta potential, surface morphology, and crystal structure, which are significant elements that regulate the actions of NPs on bacterial cells. Moreover, environmental conditions, the bacterial strain, and the exposure time are other major factors that influence the antibacterial effects of NPs. ${ }^{146}$ Many data have also shown that a large specific surface area, high surface energy, and atomic ligand deficiency lead to the aggregation of metal oxide NPs. Therefore, it is important to discuss the main factors influencing the antibacterial activity of metal oxide NPs.

\section{Size}

Bacterial adhesion is a well-known process in the formation of bacterial biofilms that makes the individual organisms much more resistant or invulnerable to conventional antibiotics. Current research has shown that the size of a metal NP can greatly affect its antibacterial activity. The diameter and length of nanotubes were adjusted by the anodic oxidation process parameter, which provides the option to prolong the release of drug against $S$. aureus. The characteristics of NPs should be given more attention when assessing antibacterial activity. ${ }^{147}$ The synergetic effect of $\mathrm{TiO}_{2}$ nanotubes and silica NPs on the antibacterial activity of composite films was demonstrated in one study, and the results indicated that the size of the $\mathrm{TiO}_{2}$ nanotubes largely determined the extent and mechanism of the antibacterial activity. ${ }^{148}$ Smaller NPs have larger specific surface areas, which result in a higher probability of being in touch with and passing through the bacterial cell membrane than with larger NPs or polymers. ${ }^{149}$ However, the sizes of three types of $\mathrm{Mg}(\mathrm{OH})_{2}$ NPs were analyzed, and the smallest $\mathrm{Mg}(\mathrm{OH})_{2}$ NPs had the weakest antibacterial effect. Thus, the size effect is not the dominant factor. Careful attention should thus be paid to the other physicochemical properties of NPs when exploring their antibacterial mechanisms. ${ }^{150}$

\section{Shape}

Shape is an important factor related to antimicrobial activity. NPs with different shapes can cause varying degrees of bacterial cell damage through interactions with periplasmic enzymes. ${ }^{151}$ A comparison of pyramid-, plate-, and sphere-shaped $\mathrm{ZnO}$ NPs showed that the combination of $\beta$-galactosidase (GAL) and shape-specific ZnO NPs produced photocatalytic activity via obstruction and restructuring of the enzyme. Pyramid-shaped n-ZnO has also been shown to prevent the degradation of enzymes. ${ }^{152}$

$\mathrm{Y}_{2} \mathrm{O}_{3}$ is widely used as an antibacterial agent with broadspectrum antimicrobial activity. Prismatic-shaped $\mathrm{Y}_{2} \mathrm{O}_{3} \mathrm{NPs}$ have shown greater antibacterial activity against $P$ seudomonas desmolyticum and S. aureus. Therefore, the shape of $\mathrm{Y}_{2} \mathrm{O}_{3}$ NPs may influence their antibacterial activity, which may be due to the direct interaction between prismatic $\mathrm{Y}_{2} \mathrm{O}_{3} \mathrm{NPs}$ and the surface of the bacterial cell membrane, leading to breakage of the bacterial cell membrane. ${ }^{153}$

Ag NPs were first applied in the field of biomedicine as sustained-release bactericidal agents. Cube-shaped Ag NPs exhibit stronger antibacterial activity than sphere-shaped and wire-shaped Ag NPs with similar diameters, suggesting that the shape effect on antibacterial activity is due to the specific surface area and facet reactivity. ${ }^{154}$ However, previous research indicated that the shape of a silver NP did not have an effect on microbiota susceptibility. ${ }^{155,156}$ 


\section{Roughness}

In contrast to the extensive research regarding the effects of different NP characteristics on bacterial cells, few studies have addressed the effect of roughness. As the roughness of NPs increases, the size and the surface area-to-mass ratio promote the adsorption of bacterial proteins, followed by a reduction in bacterial adhesion. ${ }^{157-159}$

\section{Zeta potential}

Recent studies have demonstrated that the zeta potential of NPs has a strong influence on bacterial adhesion. Because of the electrostatic attraction between positively charged NPs and the bacterial cell membrane, which is negatively charged, $\mathrm{Mg}(\mathrm{OH})_{2 \_\mathrm{MgCl}}$ and $\mathrm{Mg}(\mathrm{OH})_{2 \_\mathrm{MgSO}} \mathrm{NPs}$, which have a positive surface charge, are prone to being adsorbed on the bacterial surface and are closely connected with bacteria, in contrast to their negatively charged counterparts. ${ }^{148}$ The potential of NPs to selectively gather at sites of bacterial infection increases vascular permeability. ${ }^{160}$

Accumulation of cationic NPs is beneficial to inhibiting bacterial growth by limiting bacterial attachment. Slight penetration of NPs into the outer regions of the $S$. aureus envelope somehow provides high germicidal efficacy, possibly because the NPs can reach key structures through ion exchange. ${ }^{161}$

Compared with negatively charged and neutral NPs, positively charged counterparts have been believed to enhance ROS production. A recent study showed that negatively charged NPs do not adhere to bacteria due to the negative potential on both. However, at higher concentrations, negatively charged NPs have a certain level of antibacterial activity due to molecular crowding, which leads to interactions between the NPs and the bacterial surface. ${ }^{162}$

\section{Doping modification}

The NPs currently used in clinical settings are limited by aggregation. Many studies have employed doping modifications to prevent the aggregation of NPs and to allow NPs to disperse in aqueous environments or other hydrophilic media. Doping modification is also one of the most effective methods to regulate and control the interaction of NPs and bacteria. Lately, the combination of $\mathrm{ZnO} \mathrm{NPs}$ with $\mathrm{Au}$ to form $\mathrm{ZnO} / \mathrm{Au}$ nanocomposites has been used to improve photocatalytic activity and enhance ROS generation. These effects are a result of the following factors: improved light absorption due to the surface plasmon resonance wavelength of $\mathrm{Au}$; an altered band gap width of $\mathrm{ZnO}$, which enhances the reactivity of photoinduced charge carriers; and increased efficiency of electron transport and charge carrier separation. ${ }^{163}$ The activity of antibacterial $\mathrm{ZnO}$ can be altered by doping modification. For instance, $\mathrm{ZnO}$ NPs doped with fluorine generate more ROS than $\mathrm{ZnO} N P s$, resulting in greater damage to bacterial cells. ${ }^{164,165}$ The $\mathrm{O}$ content at the surface of the ZnO NPs is the key factor regulating antimicrobial effectiveness against both Gram-negative and Gram-positive bacteria. ${ }^{166}$

Nano- $\mathrm{TiO}_{2}$ is widely applied in orthopedic and dental implants, which have antibacterial activity that can reduce the formation of biofilms. Compared with unmodified nano$\mathrm{TiO}_{2}$, which can improve photocatalytic activity, the doped form can effectively extend the active spectrum to the visible light region because the valence bandwidth is increased and the forbidden bandwidth is reduced. ${ }^{167,168}$

\section{Environmental conditions}

A range of studies have indicated that different environmental conditions cause significant differences in antimicrobial activity. For example, the temperature of the environment has a potent influence on antibacterial activity due to its effect on the ROS generation rate. When ZnO NPs are stimulated by temperature, electrons are captured at the active sites. Afterward, the electrons interact with oxygen $\left(\mathrm{O}_{2}\right)$ to produce ROS, thereby enhancing the antimicrobial effectiveness of $\mathrm{ZnO}$ NPs. Moreover, the $\mathrm{pH}$ of the environment influences in vitro antimicrobial activity. A decrease in the $\mathrm{pH}$ increases the dissolution rate of $\mathrm{ZnO} \mathrm{NPs}$, which results in greater antimicrobial properties. ${ }^{169} \mathrm{pH}$ was specifically found to be associated with a $3.5 \pm 0.2$ - to $5.8 \pm 0.1$-fold increase in NP adhesion to the bacterial surface. In addition, the loss of efficacy of poly(lactic-co-glycolic acid) (PLGA)-poly (L-histidine) (PLH)-poly(ethylene glycol) (PEG)-encapsulated vancomycin decreased under acidic conditions. The results suggested that selective protonation of the imidazole groups of PLH under acidic conditions strongly influenced NP surface charge switching. At low $\mathrm{pH}$, the surfaces of the NPs were positively charged, which is beneficial to the interaction with the negatively charged groups of the bacterial cell barrier, inducing strong multivalent electrostatic regulation. ${ }^{170}$ Another study proposed an oxidative dissolution mechanism for Ag NPs through the interaction of $\mathrm{Ag}^{+}$with dissolved oxygen and protons. Diversification in aquatic chemistry could activate Ag NPs, enhancing the antibacterial activity of the Ag NPs due to the release of Ag ions. This study again showed that the solubility of NPs was greater in acetic acid than in neutral water. ${ }^{171}$

The characteristics of the medium, such as the $\mathrm{pH}$ and osmotic pressure, can influence the aggregation, surface 
charge, and solubility of NPs. Antibacterial tests of ZnO NPs in five types of media demonstrated that the antimicrobial activity of $\mathrm{ZnO}$ NPs is mainly due to free $\mathrm{Zn}$ ions and zinc complexes. Furthermore, the medium can supply nutrients to bacteria to improve their tolerance to NPs. ${ }^{172}$ Finally, a study has shown that preparation of $\mathrm{ZnO}$ NPs under different stirring conditions can affect their antibacterial activity against Gram-positive (B. subtilis) and Gram-negative (E. coli) bacteria and a fungus (C. albicans). ${ }^{173}$

\section{Limitations of the current research and future prospects}

The antibacterial mechanisms of NPs are still unclear. For instance, many studies attribute the antibacterial activity to oxidative stress or ROS, whereas for other NPs, such as MgO NPs, the antibacterial mechanism may not be associated with the regulation of bacterial metabolism. Therefore, the antibacterial mechanisms of NPs are worth addressing in future research.

The lack of unified standards is one limitation of the existing studies on the antibacterial mechanisms of NPs. In particular, different bacterial strains, action times, and NP characteristics have been examined in different studies, which make it difficult to compare antibacterial activity. Moreover, no single method fulfills all the conditions for obtaining information about the antibacterial mechanisms of NPs. Because different types of NPs exhibit different antibacterial effects, a comprehensive analysis is often proposed to study the potential antibacterial mechanisms. Sensitive bacterial strains are also often used to exactly determine the antibacterial activity of NPs.

Other limitations are the complex structure of the bacterial cell membrane and the lack of research approaches for in vitro studies. Furthermore, in vitro models cannot fully simulate the in vivo condition to accurately duplicate cellular interactions in the body. Therefore, it is impossible to estimate the antibacterial action of NPs through in vitro bacterial cell culture alone.

There are still many unanswered questions regarding nanoneurotoxicity, such as how NPs cross the bacterial cell membrane. The bacterial cell membrane is both a barrier and a channel for the inward and outward movement of substances. In Gram-negative bacterial cell membranes, porins, which generally allow the passage of molecules $<600 \mathrm{Da}$, are the main channels for the movement of foreign molecules into and out of the bacterial cell body. Therefore, almost the transport of nearly all NPs will be limited due to their size. However, certain scholars have proposed that porins can mediate the passage of NPs with diameters in the range of 1-9 $\mathrm{nm}$ through the bacterial cell membrane. ${ }^{174}$ Endocytosis of bacteria, similar to what is observed for eukaryotic cells, may be considered as another mechanism of NP movement. ${ }^{175}$ However, no results have been presented on this topic. Currently, the most reasonable mechanism is that bacterial cell exposure to lower concentrations of NPs causes the complete disintegration of the cells and removal of the LPS layer, which protrudes from the cell surface in the form of vesicles. Such membrane protrusions bind to NPs, which then enter the cell by electrostatic attraction.

Furthermore, studies addressing the intracellular inhibitory mechanisms remain limited. The oxidative stress induced by NPs deserves attention, and few studies have considered the action of NPs on the gene expression, protein synthesis, and metabolism of bacterial cells.

\section{Summary}

In an era of increasing MDR, in which bacteria are developing resistance to many types of antibiotics, it is becoming very difficult to fight infectious diseases and cure patients, resulting in serious morbidity and mortality. NPs are a viable alternative to antibiotics and appear to have high potential to solve the problem of the emergence of bacterial MDR. The current in-depth review of the antibacterial mechanisms may contribute to the development of efficient antibacterial NPs and to the prevention of NP cytotoxicity.

\section{Acknowledgments}

Wang and $\mathrm{Hu}$ should be considered co-first authors. This work was supported by the National Natural Science Foundation of China (31070857, 50973045, 81400557) and the Project on the Integration of Industry, Education and Research of Guangdong Province, People's Republic of China (2012B091000147).

\section{Disclosure}

The authors report no conflicts of interest in this work.

\section{References}

1. Hsueh PR. New Delhi metallo- $\beta$-lactamase-1 (NDM-1): an emerging threat among Enterobacteriaceae. J Formos Med Assoc. 2010;109(10): 685-687.

2. Poole K. Mechanisms of bacterial biocide and antibiotic resistance. J Appl Microbiol. 2002;92(suppl):55-64.

3. Jayaraman R. Antibiotic resistance: an overview of mechanisms and a paradigm shift. Curr Sci India. 2009;96(11):1475-1484.

4. Knetsch MLW, Koole LH. New strategies in the development of antimicrobial coatings: the example of increasing usage of silver and silver nanoparticles. Polymers Basel. 2011;3:340-366. 
5. Romero D, Aguilar C, Losick R, Kolter R. Amyloid fibers provide structural integrity to Bacillus subtilis biofilms. Proc Natl Acad Sci U S A. 2010;107(5):2230-2234.

6. Huh AJ, Kwon YJ. "Nanoantibiotics": a new paradigm for treating infectious diseases using nanomaterials in the antibiotics resistant era. $J$ Control Release. 2011;156(2):128-145.

7. Hajipour MJ, Fromm KM, Ashkarran AA, et al. Antibacterial properties of nanoparticles. Trends Biotechnol. 2012;30(10):499-511.

8. Reyes VC, Opot SO, Mahendra S. Planktonic and biofilm-grown nitrogen-cycling bacteria exhibit different susceptibilities to copper nanoparticles. Environ Toxicol Chem. 2015;34(4):887-897.

9. Edmundson M, Thanh NT, Song B. Nanoparticles based stem cell tracking in regenerative medicine. Theranostics. 2013;3(8):573-582.

10. Ramalingam B, Parandhaman T, Das SK. Antibacterial effects of biosynthesized silver nanoparticles on surface ultrastructure and nanomechanical properties of gram-negative bacteria viz. Escherichia coli and Pseudomonas aeruginosa. ACS Appl Mater Interfaces. 2016;8(7): 4963-4976.

11. Gurunathan S, Han JW, Dayem AA, Eppakayala V, Kim JH. Oxidative stress-mediated antibacterial activity of graphene oxide and reduced graphene oxide in Pseudomonas aeruginosa. Int J Nanomedicine. 2012; 7:5901-5914.

12. Nagy A, Harrison A, Sabbani S, Munson RS Jr, Dutta PK, Waldman WJ. Silver nanoparticles embedded in zeolite membranes: release of silver ions and mechanism of antibacterial action. Int J Nanomedicine. 2011;6: 1833-1852.

13. Leung YH, Ng AM, Xu X, et al. Mechanisms of antibacterial activity of $\mathrm{MgO}$ : non-ROS mediated toxicity of $\mathrm{MgO}$ nanoparticles towards Escherichia coli. Small. 2014;10(6):1171-1183.

14. Jung WK, Koo HC, Kim KW, Shin S, Kim SH, Park YH. Antibacterial activity and mechanism of action of the silver ion in Staphylococcus aureus and Escherichia coli. Appl Environ Microbiol. 2008;74(7): 2171-2178.

15. Khameneh B, Diab R, Ghazvini K, Fazly Bazzaz BS. Breakthroughs in bacterial resistance mechanisms and the potential ways to combat them. Microb Pathog. 2016;95:32-42.

16. Beyth N, Houri-Haddad Y, Domb A, Khan W, Hazan R. Alternative antimicrobial approach: nano-antimicrobial materials. Evid Based Complement Alternat Med. 2015;2015:246012.

17. Pelgrift RY, Friedman AJ. Nanotechnology as a therapeutic tool to combat microbial resistance. Adv Drug Deliv Rev. 2013;65(13-14): 1803-1815.

18. Mühling M, Bradford A, Readman JW, Somerfield PJ, Handy RD. An investigation into the effects of silver nanoparticles on antibiotic resistance of naturally occurring bacteria in an estuarine sediment. Mar Environ Res. 2009;68(5):278-283.

19. Qiu Z, Yu Y, Chen Z, et al. Nanoalumina promotes the horizontal transfer of multiresistance genes mediated by plasmids across genera Proc Natl Acad Sci U S A. 2012;109(13):4944-4949.

20. Aung MS, Zi H, Nwe KM, et al. Drug resistance and genetic characteristics of clinical isolates of Staphylococci in Myanmar: high prevalence of PVL among methicillin-susceptible Staphylococcus aureus belonging to various sequence types. New Microbes New Infect. 2016;10:58-65.

21. Coetzee J, Corcoran C, Prentice E, et al. Emergence of plasmid-mediated colistin resistance (MCR-1) among Escherichia coli isolated from South African patients. S Afr Med J. 2016;106(5):449-450.

22. Liu YY, Wang Y, Walsh TR, et al. Emergence of plasmid-mediated colistin resistance mechanism MCR-1 in animals and human beings in China: a microbiological and molecular biological study. Lancet Infect Dis. 2016;16(2):161-168.

23. Tsutsui M, Kawakubo H, Hayashida T, et al. Comprehensive screening of genes resistant to an anticancer drug in esophageal squamous cell carcinoma. Int J Oncol. 2015;47(3):867-874.

24. Mehdipour Moghaddam MJ, Mirbagheri AA, Salehi Z, Habibzade SM. Prevalence of class 1 integrons and extended spectrum beta lactamases among multi-drug resistant Escherichia coli isolates from north of Iran. Iran Biomed J. 2015;19(4):233-239.
25. Daury L, Orange F, Taveau JC, et al. Tripartite assembly of RND multidrug efflux pumps. Nat Commun. 2016;7:10731.

26. Lytvynenko I, Brill S, Oswald C, Pos KM. Molecular basis of polyspecificity of the small multidrug resistance efflux pump AbeS from Acinetobacter baumannii. J Mol Biol. 2016;428(3):644-657.

27. Andersson DI, Hughes D, Kubicek-Sutherland JZ. Mechanisms and consequences of bacterial resistance to antimicrobial peptides. Drug Resist Updat. 2016;26:43-57.

28. Noinaj N, Kuszak AJ, Gumbart JC, et al. Structural insight into the biogenesis of beta-barrel membrane proteins. Nature. 2013;501(7467): 385-390.

29. Chakraborty S, Gruber T, Barry CE 3rd, Boshoff HI, Rhee KY. Paraaminosalicylic acid acts as an alternative substrate of folate metabolism in Mycobacterium tuberculosis. Science. 2013;339(6115):88-91.

30. Koul A, Arnoult E, Lounis N, Guillemont J, Andries K. The challenge of new drug discovery for tuberculosis. Nature. 2011;469(7331): 483-490.

31. Yount NY, Yeaman MR. Emerging themes and therapeutic prospects for anti-infective peptides. Annu Rev Pharmacol Toxicol. 2012;52: $337-360$.

32. Singh R, Smitha MS, Singh SP. The role of nanotechnology in combating multi-drug resistant bacteria. J Nanosci Nanotechnol. 2014;14(7): 4745-4756.

33. Cavassin ED, de Figueiredo LF, Otoch JP, et al. Comparison of methods to detect the in vitro activity of silver nanoparticles (AgNP) against multidrug resistant bacteria. J Nanobiotechnology. 2015;13:64.

34. Zhang L, Pornpattananangku D, Hu CM, Huang CM. Development of nanoparticles for antimicrobial drug delivery. Curr Med Chem. 2010; 17(6):585-594.

35. Chen CW, Hsu CY, Lai SM, Syu WJ, Wang TY, Lai PS. Metal nanobullets for multidrug resistant bacteria and biofilms. Adv Drug Deliv Rev. 2014; 78:88-104.

36. Peulen TO, Wilkinson KJ. Diffusion of nanoparticles in a biofilm. Environ Sci Technol. 2011;45(8):3367-3373.

37. Yu Q, Li J, Zhang Y, Wang Y, Liu L, Li M. Inhibition of gold nanoparticles (AuNPs) on pathogenic biofilm formation and invasion to host cells. Sci Rep. 2016;6:26667.

38. Markowska K, Grudniak AM, Wolska KI. Silver nanoparticles as an alternative strategy against bacterial biofilms. Acta Biochim Pol. 2013; 60(4):523-530.

39. Lellouche J, Friedman A, Lahmi R, Gedanken A, Banin E. Antibiofilm surface functionalization of catheters by magnesium fluoride nanoparticles. Int J Nanomedicine. 2012;7:1175-1188.

40. Hetrick EM, Shin JH, Paul HS, Schoenfisch MH. Anti-biofilm efficacy of nitric oxide-releasing silica nanoparticles. Biomaterials. 2009; 30(14):2782-2789.

41. Slomberg DL, Lu Y, Broadnax AD, Hunter RA, Carpenter AW, Schoenfisch MH. Role of size and shape on biofilm eradication for nitric oxide-releasing silica nanoparticles. ACS Appl Mater Interfaces. 2013;5(19):9322-9329.

42. Miao L, Wang C, Hou J, et al. Aggregation and removal of copper oxide $(\mathrm{CuO})$ nanoparticles in wastewater environment and their effects on the microbial activities of wastewater biofilms. Bioresour Technol. 2016; 216:537-544.

43. Chifiriuc C, Grumezescu V, Grumezescu AM, Saviuc C, Lazăr V, Andronescu E. Hybrid magnetite nanoparticles/Rosmarinus officinalis essential oil nanobiosystem with antibiofilm activity. Nanoscale Res Lett. 2012;7:209.

44. Lellouche J, Friedman A, Gedanken A, Banin E. Antibacterial and antibiofilm properties of yttrium fluoride nanoparticles. Int $J$ Nanomedicine. 2012;7:5611-5624.

45. Daeihamed M, Dadashzadeh S, Haeri A, Akhlaghi MF. Potential of liposomes for enhancement of oral drug absorption. Curr Drug Deliv. Epub 2016 Jan 15.

46. Naseri N, Valizadeh H, Zakeri-Milani P. Solid lipid nanoparticles and nanostructured lipid carriers: structure, preparation and application. Adv Pharm Bull. 2015;5(3):305-313. 
47. Thukral DK, Dumoga S, Mishra AK. Solid lipid nanoparticles: promising therapeutic nanocarriers for drug delivery. Curr Drug Deliv. 2014;11(6):771-791.

48. Abed N, Couvreur P. Nanocarriers for antibiotics: a promising solution to treat intracellular bacterial infections. Int J Antimicrob Agents. 2014; 43(6):485-496.

49. Liu Y, Tee JK, Chiu GN. Dendrimers in oral drug delivery application: current explorations, toxicity issues and strategies for improvement. Curr Pharm Des. 2015;21(19):2629-2642.

50. Ranghar S. Nanoparticle-based drug delivery systems: promising approaches against infections. Braz Arch Biol Techn. 2012;57: 209-222.

51. Andrade F, Rafael D, Videira M, Ferreira D, Sosnik A, Sarmento B. Nanotechnology and pulmonary delivery to overcome resistance in infectious diseases. Adv Drug Deliver Rev. 2013;65(13-14):1816-1827.

52. Qi G, Li L, Yu F, Wang H. Vancomycin-modified mesoporous silica nanoparticles for selective recognition and killing of pathogenic gram-positive bacteria over macrophage-like cells. ACS Appl Mater Interfaces. 2013;5(21):10874-10881.

53. Xiong MH, Li YJ, Bao Y, Yang XZ, Hu B, Wang J. Bacteria-responsive multifunctional nanogel for targeted antibiotic delivery. Adv Mater. 2012; 24(46):6175-6180.

54. Liu JL, Zhang WJ, Li XD, et al. Sustained-release genistein from nanostructured lipid carrier suppresses human lens epithelial cell growth. Int J Ophthalmol. 2016;9(5):643-649.

55. Wu J, Shen Y, Jiang W, Jiang W, Shen Y. Magnetic targeted drug delivery carriers encapsulated with $\mathrm{pH}$-sensitive polymer: synthesis, characterization and in vitro doxorubicin release studies. $J$ Biomater Sci Polym Ed. 2016;27(13):1303-1316.

56. Lv Y, Hao L, Hu W, Ran Y, Bai Y, Zhang L. Novel multifunctional $\mathrm{pH}$-sensitive nanoparticles loaded into microbubbles as drug delivery vehicles for enhanced tumor targeting. Sci Rep. 2016;6:29321.

57. Lim EK, Chung BH, Chung SJ. Recent advances in $\mathrm{pH}$-sensitive polymeric nanoparticles for smart drug delivery in cancer therapy. Curr Drug Targets. Epub 2016 Jun 2.

58. Yun S, Huang JJ. Routes for drug delivery: sustained-release devices. Dev Ophthalmol. 2016;55:84-92.

59. Baig MS, Ahad A, Aslam M, Imam SS, Aqil M, Ali A. Application of Box-Behnken design for preparation of levofloxacin-loaded stearic acid solid lipid nanoparticles for ocular delivery: optimization, in vitro release, ocular tolerance, and antibacterial activity. Int J Biol Macromol. 2016;85:258-270.

60. Hadinoto K, Sundaresan A, Cheow WS. Lipid-polymer hybrid nanoparticles as a new generation therapeutic delivery platform: a review. Eur J Pharm Biopharm. 2013;85(3 pt A):427-443.

61. Brooks BD, Brooks AE. Therapeutic strategies to combat antibiotic resistance. Adv Drug Deliv Rev. 2014;78:14-27.

62. Xia W, Grandfield K, Hoess A, Ballo A, Cai Y, Engqvist H. Mesoporous titanium dioxide coating for metallic implants. J Biomed Mater Res B Appl Biomater. 2012;100(1):82-93.

63. Della Valle C, Visai L, Santin M, et al. A novel antibacterial modification treatment of titanium capable to improve osseointegration. Int J Artif Organs. 2012;35(10):864-875.

64. Samuel U, Guggenbichler JP. Prevention of catheter-related infections: the potential of a new nano-silver impregnated catheter. Int J Antimicrob Agents. 2004;23(suppl 1):75-78.

65. Galiano K, Pleifer C, Engelhardt K, et al. Silver segregation and bacterial growth of intraventricular catheters impregnated with silver nanoparticles in cerebrospinal fluid drainages. Neurol Res. 2008;30(3): 285-287.

66. Yu C, Hu ZQ, Peng RY. Effects and mechanisms of a microcurrent dressing on skin wound healing: a review. Mil Med Res. 2014;1:24.

67. Li C, Fu R, Yu C, et al. Silver nanoparticle/chitosan oligosaccharide/ poly (vinylalcohol) nanofibers as wound dressings: a preclinical study. Int J Nanomedicine. 2013;8:4131-4145.

68. Kreutzer J, Schneider M, Schlegel U, Ewerbeck V, Breusch SJ. Cemented total hip arthroplasty in Germany-update. Z Orthop Ihre Grenzgeb. 2005;143(1):48-55.
69. Nowinski RJ, Gillespie RJ, Shishani Y, Cohen B, Walch G, Gobezie R. Antibiotic-loaded bone cement reduces deep infection rates for primary reverse total shoulder arthroplasty: a retrospective, cohort study of 501 shoulders. J Shoulder Elbow Surg. 2012;21(3):324-328.

70. Zhou Y, Li L, Zhou Q, et al. Lack of efficacy of prophylactic application of antibiotic-loaded bone cement for prevention of infection in primary total knee arthroplasty: results of a meta-analysis. Surg Infect (Larchmt). 2015;16(2):183-187.

71. Hinarejos P, Guirro P, Leal J, et al. The use of erythromycin and colistin-loaded cement in total knee arthroplasty does not reduce the incidence of infection: a prospective randomized study in 3000 knees. J Bone Joint Surg Am. 2013;95(9):769-774.

72. Miola M, Fucale G, Maina G, Verné E. Antibacterial and bioactive composite bone cements containing surface silver-doped glass particles. Biomed Mater. 2015;10(5):055014.

73. Kose N, Çaylak R, Pekşen C, et al. Silver ion doped ceramic nanopowder coated nails prevent infection in open fractures: in vivo study. Injury. 2016;47(2):320-324.

74. Prokopovich P, Köbrick M, Brousseau E, Perni S. Potent antimicrobial activity of bone cement encapsulating silver nanoparticles capped with oleic acid. J Biomed Mater Res B Appl Biomater. 2015;103(2): 273-281.

75. Lee DK, Kim SV, Limansubroto AN, et al. Nanodiamond-gutta percha composite biomaterials for root canal therapy. ACS Nano. 2015;9(11): 11490-11501.

76. Ramazanzadeh B, Jahanbin A, Yaghoubi M, et al. Comparison of antibacterial effects of $\mathrm{ZnO}$ and $\mathrm{CuO}$ nanoparticles coated brackets against Streptococcus mutans. J Dent (Shiraz). 2015;16(3): 200-205.

77. Aboelzahab A, Azad AM, Dolan S, Goel V. Mitigation of Staphylococcus aureus-mediated surgical site infections with Ir photoactivated $\mathrm{TiO}_{2}$ coatings on Ti implants. Adv Healthc Mater. 2012;1(3):285-291.

78. Moreno-Sastre M, Pastor M, Esquisabel A, et al. Pulmonary delivery of tobramycin-loaded nanostructured lipid carriers for Pseudomonas aeruginosa infections associated with cystic fibrosis. Int $J$ Pharm. 2016;498(1-2):263-273.

79. Ahmad E, Fatima MT, Hoque M, Owais M, Saleemuddin M. Fibrin matrices: the versatile therapeutic delivery systems. Int J Biol Macromol. 2015;81:121-136.

80. Patra S, Roy E, Karfa P, Kumar S, Madhuri R, Sharma PK. Dual-responsive polymer coated superparamagnetic nanoparticle for targeted drug delivery and hyperthermia treatment. ACS Appl Mater Interfaces. 2015; 7(17):9235-9246.

81. Oliveira RR, Ferreira FS, Cintra ER, Branquinho LC, Bakuzis AF, Lima EM. Magnetic nanoparticles and rapamycin encapsulated into polymeric nanocarriers. J Biomed Nanotechnol. 2012;8(2):193-201.

82. Huang YC, Li RY, Chen JY, Chen JK. Biphasic release of gentamicin from chitosan/fucoidan nanoparticles for pulmonary delivery. Carbohyd Polym. 2016;138:114-122.

83. Costa JR, Silva NC, Sarmento B, Pintado M. Potential chitosan-coated alginate nanoparticles for ocular delivery of daptomycin. Eur J Clin Microbiol Infect Dis. 2015;34(6):1255-1262.

84. Chatzimitakos TG, Stalikas CD. Qualitative alterations of bacterial metabolome after exposure to metal nanoparticles with bactericidal properties: a comprehensive workflow based on ${ }^{1} \mathrm{H}$ NMR, UHPLC-HRMS and metabolic databases. J Proteome Res. 2016;15(9):3322-3330.

85. Zhao L, Ashraf MA. Influence of silver-hydroxyapatite nanocomposite coating on biofilm formation of joint prosthesis and its mechanism. West Indian Med J. Epub 2016 Apr 18.

86. Li H, Chen Q, Zhao J, Urmila K. Enhancing the antimicrobial activity of natural extraction using the synthetic ultrasmall metal nanoparticles. Sci Rep. 2015;5:11033.

87. Armentano I, Arciola CR, Fortunati E, et al. The interaction of bacteria with engineered nanostructured polymeric materials: a review. Scientific World J. 2014;2014:410423.

88. Gao W, Thamphiwatana S, Angsantikul P, Zhang L. Nanoparticle approaches against bacterial infections. Wires Nanomed Nanobi. 2014; 6(6):532-547. 
89. Luan B, Huynh T, Zhou R. Complete wetting of graphene by biological lipids. Nanoscale. 2016;8(10):5750-5754.

90. Xu Y, Wei MT, Ou-Yang HD, et al. Exposure to $\mathrm{TiO}_{2}$ nanoparticles increases Staphylococcus aureus infection of HeLa cells. J Nanobiotechnology. 2016;14:34.

91. Shrivastava S, Bera T, Roy A, Dash D. Characterization of enhanced antibacterial effects of novel silver nanoparticles. Nanotechnology. 2007; 18(22):225103

92. Yang W, Shen C, Ji Q, et al. Food storage material silver nanoparticles interfere with DNA replication fidelity and bind with DNA. Nanotechnology. 2009;20(8):085102.

93. Zakharova OV, Godymchuk AY, Gusev AA, Gulchenko SI, Vasyukova IA, Kuznetsov DV. Considerable variation of antibacterial activity of $\mathrm{Cu}$ nanoparticles suspensions depending on the storage time, dispersive medium, and particle sizes. Biomed Res Int. 2015;2015: 412530.

94. Malka E, Perelshtein I, Lipovsky A, et al. Eradication of multi-drug resistant bacteria by a novel $\mathrm{Zn}$-doped $\mathrm{CuO}$ nanocomposite. Small. 2013;9(23):4069-4076.

95. Li Y, Zhang W, Niu J, Chen Y. Mechanism of photogenerated reactive oxygen species and correlation with the antibacterial properties of engineered metal-oxide nanoparticles. ACS Nano. 2012;6(6):5164-5173.

96. Peng Z, Ni J, Zheng K, et al. Dual effects and mechanism of $\mathrm{TiO}_{2}$ nanotube arrays in reducing bacterial colonization and enhancing $\mathrm{C}_{3} \mathrm{H}_{10} \mathrm{~T}_{12}$ cell adhesion. Int J Nanomedicine. 2013;8:3093-3105.

97. Cheloni G, Marti E, Slaveykova VI. Interactive effects of copper oxide nanoparticles and light to green alga Chlamydomonas reinhardtii. Aquat Toxicol. 2016;170:120-128.

98. Ansari MA, Khan HM, Alzohairy MA, et al. Green synthesis of $\mathrm{Al}_{2} \mathrm{O}_{3}$ nanoparticles and their bactericidal potential against clinical isolates of multi-drug resistant Pseudomonas aeruginosa. World J Microb Biot. 2015;31(1):153-164.

99. Pramanik A, Laha D, Bhattacharya D, Pramanik P, Karmakar P. A novel study of antibacterial activity of copper iodide nanoparticle mediated by DNA and membrane damage. Colloid Surface B. 2012;96:50-55.

100. Wu B, Zhuang WQ, Sahu M, Biswas P, Tang YJ. Cu-doped TiO 2 nanoparticles enhance survival of Shewanella oneidensis MR-1 under ultraviolet (UV) light exposure. Sci Total Environ. 2011;409(21):4635-4639.

101. Padmavathy $\mathrm{N}$, Vijayaraghavan $\mathrm{R}$. Interaction of $\mathrm{ZnO}$ nanoparticles with microbes - a physio and biochemical assay. $J$ Biomed Nanotechnol. 2011;7(6):813-822.

102. Yu J, Zhang W, Li Y, et al. Synthesis, characterization, antimicrobial activity and mechanism of a novel hydroxyapatite whisker/nano zinc oxide biomateriali. Biomed Mater. 2014;10(1):015001.

103. Depan D, Misra RD. On the determining role of network structure titania in silicone against bacterial colonization: mechanism and disruption of biofilm. Mater Sci Eng C Mater Biol Appl. 2014;34:221-228.

104. Matai I, Sachdev A, Dubey P, Kumar SU, Bhushan B, Gopinath P. Antibacterial activity and mechanism of $\mathrm{Ag}-\mathrm{ZnO}$ nanocomposite on S. aureus and GFP-expressing antibiotic resistant E. coli. Colloids Surf B Biointerfaces. 2014;115:359-367.

105. Seil JT, Webster TJ. Antibacterial effect of zinc oxide nanoparticles combined with ultrasound. Nanotechnology. 2012;23(49):495101.

106. Xu X, Chen D, Yi Z, et al. Antimicrobial mechanism based on $\mathrm{H}_{2} \mathrm{O}_{2}$ generation at oxygen vacancies in $\mathrm{ZnO}$ crystals. Langmuir. 2013; 29(18):5573-5580.

107. Hussein-Al-Ali SH, El Zowalaty ME, Hussein MZ, Geilich BM, Webster TJ. Synthesis, characterization, and antimicrobial activity of an ampicillin-conjugated magnetic nanoantibiotic for medical applications. Int J Nanomedicine. 2014;9:3801-3814.

108. Lesniak A, Salvati A, Santos-Martinez MJ, Radomski MW, Dawson KA, Åberg C. Nanoparticle adhesion to the cell membrane and its effect on nanoparticle uptake efficiency. J Am Chem Soc. 2013;135(4):1438-1444.

109. Sarwar A, Katas H, Samsudin SN, Zin NM. Regioselective sequential modification of chitosan via azide-alkyne click reaction: synthesis, characterization, and antimicrobial activity of ahitosan derivatives and nanoparticles. PLoS One. 2015;10(4):e0123084.
110. Hyldgaard M, Mygind T, Vad BS, Stenvang M, Otzen DE, Meyer RL. The antimicrobial mechanism of action of epsilon-poly-1-lysine. Appl Environ Microbiol. 2014;80(24):7758-7770.

111. Wehling J, Dringen R, Zare R, Mass M, Rezwan K. Bactericidal activity of partially oxidized nanodiamonds. ACS Nano. 2014;8(6): 6475-6483.

112. Foster HA, Ditta IB, Varghese S, Steele A. Photocatalytic disinfection using titanium dioxide: spectrum and mechanism of antimicrobial activity. Appl Microbiol Biotechnol. 2011;90(6):1847-1868.

113. Joost U, Juganson K, Visnapuu M, et al. Photocatalytic antibacterial activity of nano- $\mathrm{TiO}_{2}$ (anatase)-based thin film: effects on Escherichia coli cells and fatty acids. $J$ Photochem Photobiol B. 2015;14: 178-185.

114. Sultana P, Das S, Bhattacharya A, Basu R, Nandy P. Development of iron oxide and titania treated fly ash based ceramic and its bioactivity. Mater Sci Eng C Mater Biol Appl. 2012;32(6):1358-1365.

115. Zhukova LV. Evidence for compression of Escherichia coli K12 cells under the effect of $\mathrm{TiO}_{2}$ nanoparticles. ACS Appl Mater Interfaces. 2015; 7(49):27197-27205.

116. Tu YS, Lv M, Xiu P, et al. Destructive extraction of phospholipids from Escherichia coli membranes by graphene nanosheets. Nat Nanotechnol. 2013;8(12):594-601.

117. Akhavan O, Ghaderi E. Toxicity of graphene and graphene oxide nanowalls against bacteria. ACS Nano. 2010;4(10):5731-5736.

118. Sohm B, Immel F, Bauda P, Pagnout C. Insight into the primary mode of action of $\mathrm{TiO}_{2}$ nanoparticles on Escherichia coli in the dark. Proteomics. 2015;15(1):98-113.

119. Ansari MA, Khan HM, Khan AA, Cameotra SS, Saquib Q, Musarrat J. Interaction of $\mathrm{Al}_{2} \mathrm{O}_{3}$ nanoparticles with Escherichia coli and their cell envelope biomolecules. J Appl Microbiol. 2014;116(4):772-783.

120. Erdem A, Metzler D, Cha DK, Huang CP. The short-term toxic effects of $\mathrm{TiO}_{2}$ nanoparticles toward bacteria through viability, cellular respiration, and lipid peroxidation. Environ Sci Pollut Res Int. 2015; 22(22):17917-17924.

121. Sondi I, Salopek-Sondi B. Silver nanoparticles as antimicrobial agent: a case study on E. coli as a model for gram-negative bacteria. J Colloid Interf Sci. 2004;275(1):177-182.

122. Nataraj N, Anjusree GS, Madhavan AA, et al. Synthesis and antiStaphylococcal activity of $\mathrm{TiO}_{2}$ nanoparticles and nanowires in ex vivo porcine skin model. J Biomed Nanotechnol. 2014;10(5):864-870.

123. Pan WY, Huang CC, Lin TT, et al. Synergistic antibacterial effects of localized heat and oxidative stress caused by hydroxyl radicals mediated by graphene/iron oxide-based nanocomposites. Nanomedicine. 2016;12(2):431-438

124. Zhang W, Li Y, Niu JF, Chen YS. Photogeneration of reactive oxygen species on uncoated silver, gold, nickel, and silicon nanoparticles and their antibacterial effects. Langmuir. 2013;29(15):4647-4651.

125. Mukha IP, Eremenko AM, Smirnova NP, et al. Antimicrobial activity of stable silver nanoparticles of a certain size. Appl Biochem Micro. 2013; 49(2):199-206.

126. Lin JQ, Zhang HW, Chen Z, Zheng YG. Penetration of lipid membranes by gold nanoparticles: insights into cellular uptake, cytotoxicity, and their relationship. ACS Nano. 2010;4(9):5421-5429.

127. Su Y, Zheng X, Chen Y, Li M, Liu K. Alteration of intracellular protein expressions as a key mechanism of the deterioration of bacterial denitrification caused by copper oxide nanoparticles. Sci Rep. 2015;5: 15824.

128. Yamanaka M, Hara K, Kudo J. Bactericidal actions of a silver ion solution on Escherichia coli, studied by energy-filtering transmission electron microscopy and proteomic analysis. Appl Environ Microb. 2005; 71(11):7589-7593.

129. Cui Y, Zhao YY, Tian Y, Zhang W, Lü XY, Jiang XY. The molecular mechanism of action of bactericidal gold nanoparticles on Escherichia coli. Biomaterials. 2011;33(7):2327-2333.

130. Iram NE, Khan MS, Jolly R, et al. Interaction mode of polycarbazoletitanium dioxide nanocomposite with DNA: molecular docking simulation and in-vitro antimicrobial study. J Photochem Photobiol. 2015; 153:20-32. 
131. Su G, Zhang X, Giesy JP, et al. Comparison on the molecular response profiles between nano zinc oxide $(\mathrm{ZnO})$ particles and free zinc ion using a genome-wide toxicogenomic approach. Environ Sci Pollut Res Int. 2015;22(22):17434-17442.

132. Niemirowicz K, Swiecicka I, Wilczewska AZ, et al. Gold-functionalized magnetic nanoparticles restrict growth of Pseudomonas aeruginosa. Int J Nanomedicine. 2014;9:2217-2224.

133. Bajpai AK, Gupta R. Magnetically mediated release of ciprofloxacin from polyvinyl alcohol based superparamagnetic nanocomposites. J Mater Sci Mater Med. 2011;22(2):357-369.

134. Durmus NG, Taylor EN, Inci F, Kummer K, Tarquinio KM, Webster TJ. Fructose-enhanced reduction of bacterial growth on nanorough surfaces. Int J Nanomedicine. 2012;7:537-545.

135. Leuba KD, Durmus NG, Taylor EN, Webster TJ. Short communication: carboxylate functionalized superparamagnetic iron oxide nanoparticles (SPION) for the reduction of $S$. aureus growth post biofilm formation. Int J Nanomedicine. 2013;8:731-736.

136. Roguska A, Belcarz A, Pisarek M, Ginalska G, Lewandowska M. $\mathrm{TiO}_{2}$ nanotube composite layers as delivery system for $\mathrm{ZnO}$ and $\mathrm{Ag}$ nanoparticles - an unexpected overdose effect decreasing their antibacterial efficacy. Mater Sci Eng C Mater Biol Appl. 2015;51:158-166.

137. Pan F, Xu A, Xia D, et al. Effects of octahedral molecular sieve on treatment performance, microbial metabolism, and microbial community in expanded granular sludge bed reactor. Water Res. 2015;87: 127-136.

138. Qiu W, Zheng X, Wei Y, et al. D-alanine metabolism is essential for growth and biofilm formation of Streptococcus mutans. Mol Oral Microbiol. 2016;31(5):435-444.

139. Su HL, Chou CC, Hung DJ, et al. The disruption of bacterial membrane integrity through ROS generation induced by nanohybrids of silver and clay. Biomaterials. 2009;30(30):5979-5987.

140. Ansari MA, Khan HM, Khan AA, Sultan A, Azam A. Synthesis and characterization of the antibacterial potential of $\mathrm{ZnO}$ nanoparticles against extended-spectrum $\beta$-lactamases-producing Escherichia coli and Klebsiella pneumoniae isolated from a tertiary care hospital of north India. Appl Microbiol Biotechnol. 2012;94(2):467-477.

141. Wilking JN, Zaburdaev V, De Volder M, Losick R, Brenner MP, Weitz DA. Liquid transport facilitated by channels in Bacillus subtilis biofilms. Proc Natl Acad Sci U S A. 2013;110(3):848-852.

142. Mohanty S, Mishra S, Jena P, Jacob B, Sarkar B, Sonawane A. An investigation on the antibacterial, cytotoxic, and antibiofilm efficacy of starch-stabilized silver nanoparticles. Nanomedicine. 2012;8(6): 916-924.

143. Lundberg ME, Becker EC, Choe S. MstX and a putative potassium channel facilitate biofilm formation in Bacillus subtilis. PLoS One. 2013;8(5):e60993.

144. Lellouche J, Friedman A, Lellouche JP, Gedanken A, Banin E. Improved antibacterial and antibiofilm activity of magnesium fluoride nanoparticles obtained by water-based ultrasound chemistry. Nanomedicine. 2012;8(5):702-711.

145. Salem W, Leitner DR, Zingl FG, et al. Antibacterial activity of silver and zinc nanoparticles against Vibrio cholerae and enterotoxic Escherichia coli. Int J Med Microbiol. 2015;305(1):85-95.

146. Çalışkan N, Bayram C, Erdal E, Karahaliloğlu Z, Denkbaş EB. Titania nanotubes with adjustable dimensions for drug reservoir sites and enhanced cell adhesion. Mater Sci Eng C Mater Biol Appl. 2014;35: 100-105.

147. Esfandiari N, Simchi A, Bagheri R. Size tuning of Ag-decorated $\mathrm{TiO}_{2}$ nanotube arrays for improved bactericidal capacity of orthopedic implants. J Biomed Mater Res A. 2014;102(8):2625-2635.

148. Pan X, Wang $Y$, Chen Z, et al. Investigation of antibacterial activity and related mechanism of a series of nano- $\mathrm{Mg}(\mathrm{OH})_{2}$. ACS Appl Mater Interfaces. 2013;5(3):1137-1142.

149. Gurunathan S, Han JW, Kwon DN, Kim JH. Enhanced antibacterial and anti-biofilm activities of silver nanoparticles against gram-negative and gram-positive bacteria. Nanoscale Res Lett. 2014;9(1):373.
150. Deplanche K, Caldelari I, Mikheenko IP, Sargent F, Macaskie LE. Involvement of hydrogenases in the formation of highly catalytic $\operatorname{Pd}(0)$ nanoparticles by bioreduction of $\mathrm{Pd}(\mathrm{II})$ using Escherichia coli mutant strains. Microbiology. 2010;156(9):2630-2640.

151. Cha SH, Hong J, McGuffie M, Yeom B, VanEpps JS, Kotov NA. Shape-dependent biomimetic inhibition of enzyme by nanoparticles and their antibacterial activity. ACS Nano. 2015;9(9):9097-9105.

152. Prasannakumar JB, Vidya YS, Anantharaju KS, et al. Bio-mediated route for the synthesis of shape tunable $\mathrm{Y}_{2} \mathrm{O}_{3}: \mathrm{Tb}^{3+}$ nanoparticles: photoluminescence and antibacterial properties. Spectrochim Acta A Mol Biomol Spectrosc. 2015;151:131-140.

153. Hong X, Wen J, Xiong X, Hu Y. Shape effect on the antibacterial activity of silver nanoparticles synthesized via a microwave-assisted method. Environ Sci Pollut Res Int. 2016;23(5):4489-4497.

154. Actis L, Srinivasan A, Lopez-Ribot JL, Ramasubramanian AK, Ong JL. Effect of silver nanoparticle geometry on methicillin susceptible and resistant Staphylococcus aureus, and osteoblast viability. J Mater Sci Mater Med. 2015;26(7):215.

155. Talebian N, Sadeghi Haddad Zavvare H. Enhanced bactericidal action of $\mathrm{SnO}_{2}$ nanostructures having different morphologies under visible light: influence of surfactant. J Photochem Photobiol B. 2014;130: 132-139.

156. Gao M, Sun L, Wang Z, Zhao Y. Controlled synthesis of Ag nanoparticles with different morphologies and their antibacterial properties. Mater Sci Eng C Mater Biol Appl. 2013;33(1):397-404.

157. Ben-Sasson M, Zodrow KR, Genggeng Q, Kang Y, Giannelis EP, Elimelech M. Surface functionalization of thin-film composite membranes with copper nanoparticles for antimicrobial surface properties. Environ Sci Technol. 2014;48(1):384-393.

158. Rajakumar G, Rahuman AA, Roopan SM, et al. Fungus-mediated biosynthesis and characterization of $\mathrm{TiO}_{2}$ nanoparticles and their activity against pathogenic bacteria. Spectrochim Acta A Mol Biomol Spectrosc. 2012;91:23-29.

159. Sukhorukova IV, Sheveyko AN, Kiryukhantsev-Korneev PV, et al. Toward bioactive yet antibacterial surfaces. Colloid Surface B. 2015; 135:158-165.

160. Maeda H. Tumor-selective delivery of macromolecular drugs via the EPR effect: background and future prospects. Bioconjug Chem. 2010; 21(5):797-802.

161. Fang B, Jiang Y, Nüsslein K, Rotello VM, Santore MM. Antimicrobial surfaces containing cationic nanoparticles: how immobilized, clustered, and protruding cationic charge presentation affects killing activity and kinetics. Colloid Surface B. 2015;125:255-263.

162. Arakha M, Pal S, Samantarrai D, et al. Antimicrobial activity of iron oxide nanoparticle upon modulation of nanoparticle-bacteria interface. Sci Rep. 2015;5:14813.

163. He W, Kim HK, Wamer WG, Melka D, Callahan JH, Yin JJ. Photogenerated charge carriers and reactive oxygen species in $\mathrm{ZnO} / \mathrm{Au}$ hybrid nanostructures with enhanced photocatalytic and antibacterial activity. J Am Chem Soc. 2014;136(2):750-757.

164. Podporska-Carroll J, Myles A, Quilty B, et al. Antibacterial properties of F-doped $\mathrm{ZnO}$ visible light photocatalyst. J Hazard Mater. 2017;324(pt A):39-47.

165. Guo BL, Han P, Guo LC, et al. The antibacterial activity of Ta-doped ZnO nanoparticles. Nanoscale Res Lett. 2015;10(1):1047.

166. Mehmood S, Rehman MA, Ismail H, Mirza B, Bhatti AS. Significance of postgrowth processing of $\mathrm{ZnO}$ nanostructures on antibacterial activity against gram-positive and gram-negative bacteria. Int J Nanomedicine. 2015;10:4521-4533.

167. Sangari M, Umadevi M, Mayandi J, Pinheiro JP. Photocatalytic degradation and antimicrobial applications of F-doped MWCNTs/ $\mathrm{TiO}_{2}$ composites. Spectrochim Acta A Mol Biomol Spectrosc. 2015; 139:290-295.

168. Peng YP, Lo SL, Ou HH, Lai SW. Microwave-assisted hydrothermal synthesis of $\mathrm{N}$-doped titanate nanotubes for visible-light-responsive photocatalysis. J Hazard Mater. 2010;183(1-3):754-758. 
169. Saliani M, Jalal R, Kafshdare Goharshadi E. Effects of $\mathrm{pH}$ and temperature on antibacterial activity of zinc oxide nanofluid against Escherichia coli O157:H7 and Staphylococcus aureus. Jundishapur J Microbiol. 2015;8(2):e17115.

170. Radovic-Moreno AF, Lu TK, Puscasu VA, Yoon CJ, Langer R, Farokhzad OC. Surface charge-switching polymeric nanoparticles for bacterial cell wall-targeted delivery of antibiotics. ACS Nano. 2012; 6(5):4279-4287.

171. Peretyazhko TS, Zhang Q, Colvin VL. Size-controlled dissolution of silver nanoparticles at neutral and acidic $\mathrm{pH}$ conditions: kinetics and size changes. Environ Sci Technol. 2014;48(20):11954-11961.

172. Li M, Zhu L, Lin D. Toxicity of $\mathrm{ZnO}$ nanoparticles to Escherichia coli: mechanism and the influence of medium components. Environ Sci Technol. 2011;45(5):1977-1983.
173. Khan MF, Ansari AH, Hameedullah M, et al. Sol-gel synthesis of thorn-like $\mathrm{ZnO}$ nanoparticles endorsing mechanical stirring effect and their antimicrobial activities: potential role as nano-antibiotics. Sci Rep. 2016;6:27689.

174. Neal AL. What can be inferred from bacterium-nanoparticle interactions about the potential consequences of environmental exposure to nanoparticles. Ecotoxicology. 2008;17(5):362-371.

175. Lai HZ, Chen WY, Wu CY, Chen YC. Potent antibacterial nanoparticles for pathogenic bacteria. ACS Appl Mater Interfaces. 2015;7(3): 2046-2054.
International Journal of Nanomedicine

\section{Publish your work in this journal}

The International Journal of Nanomedicine is an international, peerreviewed journal focusing on the application of nanotechnology in diagnostics, therapeutics, and drug delivery systems throughout the biomedical field. This journal is indexed on PubMed Central, MedLine, CAS, SciSearch $®$, Current Contents $® /$ Clinical Medicine,

\section{Dovepress}

Journal Citation Reports/Science Edition, EMBase, Scopus and the Elsevier Bibliographic databases. The manuscript management system is completely online and includes a very quick and fair peer-review system, which is all easy to use. Visit http://www.dovepress.com/ testimonials.php to read real quotes from published authors.

Submit your manuscript here: http://www.dovepress.com/international-journal-of-nanomedicine-journal 